Universidade de São Paulo

Faculdade de Saúde Pública

\title{
A influência do peso ao nascer sobre a pressão arterial e a composição corporal em crianças.
}

\section{Joilane Alves Pereira}

Dissertação apresentada ao Programa de PósGraduação em Saúde Pública para obtenção do título de Mestre em Saúde Pública.

Área de concentração: Nutrição

Orientadora: Prof ${ }^{\mathrm{a}}$. Dr ${ }^{\mathrm{a}}$. Patrícia Helen de Carvalho Rondó

São Paulo 


\section{A influência do peso ao nascer sobre a pressão arterial e a composição corporal em crianças.}

\section{Joilane Alves Pereira}

Dissertação apresentada ao Programa de

Pós-Graduação em Saúde Pública da

Faculdade de Saúde Pública da

universidade de São Paulo, para obtenção

do título de Mestre em Saúde Pública.

Área de concentração: Nutrição

Orientadora: Prof ${ }^{\mathrm{a}}$. Dr ${ }^{\mathrm{a}}$. Patrícia Helen de

Carvalho Rondó

São Paulo

2007 
Autorizo, exclusivamente para fins acadêmicos e científicos, a reprodução total ou parcial desta dissertação. Em caso de utilização é obrigatória a citação da fonte no texto, com a respectiva referência bibliográfica.

Citação sugerida: Pereira JA. A influência do peso ao nascer sobre a pressão arterial e a composição corporal em crianças de Jundiaí, SP. [Dissertação de Mestrado]. São Paulo: Faculdade de Saúde Pública da Universidade de São Paulo; 2007.

Joilane Alves Pereira

São Paulo, outubro de 2007 


\section{Dedicatória}

Dedico aos meus pais José e Oniranda que me apoiaram mesmo sem compreender o significado deste trabalho. O meu amor e gratidão por vocês são enormes.

Aos meus irmãos (Joyce, Jonilsom, Joelsom e Joel) que me fizeram compreender que o mais importante na vida não é a situação em que estamos, mas a direção para a qual nos movemos. Por vocês eu pude continuar...!!

À Igreja Batista Boas Novas de Jundiaí, pelo apoio prestado quando cheguei à cidade. Especialmente à Sandra Galli e família, por todo o carinho e confiança que tiveram em mim. A vocês o meu especial: MUITO $O B R I G A D A !$

À todas as crianças e mães que tive o prazer de conhecer e conviver durante o desenvolvimento dessa pesquisa. 


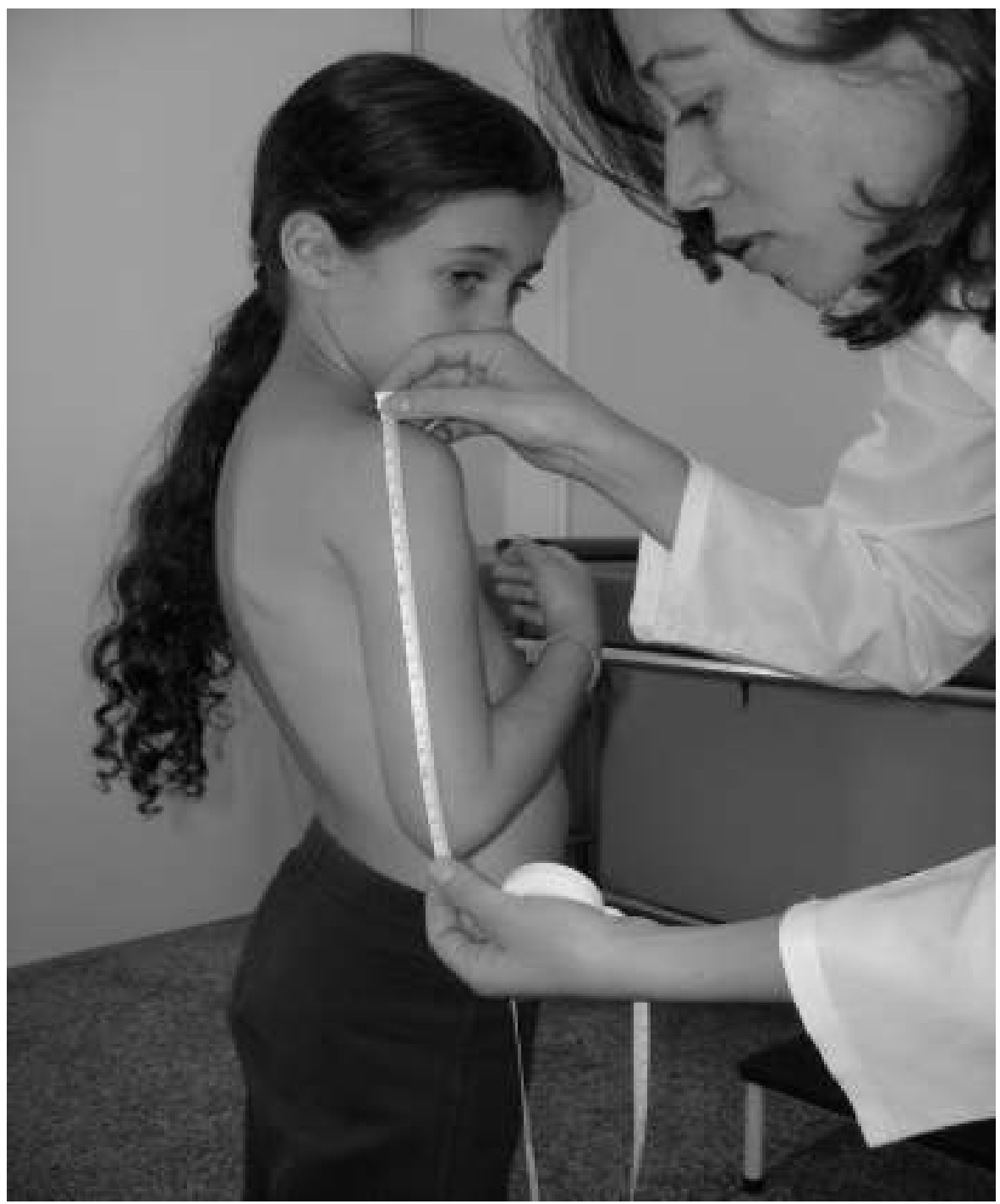

"Cada criança, ao nascer, traz-nos a mensagem de que Deus ainda não perdeu a esperança nos homens (Tagore)".

Que o nosso trabalho seja cooperar com Deus por um mundo melhor..!!! 


\title{
Agradecimentos
}

Este trabalho foi realizado graças ao apoio, incentivo e amizade de velhos e novos amigos, a quem tenho muito que agradecer:

\begin{abstract}
À Deus, que em todas as etapas me provou que as adversidades despertam em nós capacidades que teriam ficado adormecidas se existissem apenas circunstâncias favoráveis. Realmente todos os obstáculos por fim tornaram-se aprendizado, portanto a Ti agradeço pela oportunidade de evolução profissional e espiritual.
\end{abstract}

À minha família, mamãe e papai, irmãos e irmã, que participaram de tantos imprevistos e dos momentos de insegurança... Agora compartilho com vocês toda a minha felicidade...!!

À Profa. Dra. Patrícia Helen de Carvalho Rondó, minha orientadora, agradeço pela orientação, tranqüila e competente; pela dedicação; bem como pela confiança em mim depositada. Sem dúvida um exemplo de mulher corajosa, forte e batalhadora. 
Ao Prof. Dr. José Maria Pacheco e Dr Raul Santos pela valiosa contribuição para o aprimoramento da dissertação e na ocasião da defesa da mesma.

À Dra Adriana de Azevedo Paiva, pela confiança depositada em mim, por ter sido exemplo de coragem e por me mostrar que era possível a realização desse sonho. Não conseguiria expressar minha gratidão a você. Mas pode contar comigo para o que der e vier..!!!

À Jesuana Lemos, pela maturidade e competência, o meu obrigada e o desejo de que consiga realizar-se onde estiver. Às amigas da pós-graduação Vanessa, Andréia, Lígia e Julie Christie pelos conselhos, apoio, partilha dos momentos fáceis e difíceis, e pela amizade conquistada.

Às alunas do curso de nutrição da USP: Camila e Selma Rico Alencar, que trabalharam conosco voluntariamente e sempre estiveram disponíveis quando mais precisávamos. À Selminha, que um dia eu possa retribuir por tudo...!

E um OBRIGADA muito especial a Sheyla e Josimara, amigas da graduação...Quantos momentos!! Entre alegrias e dificuldades, guardo as boas lembranças..!! E a certeza de que não teria conseguido fazer metade do que foi 
realizado sem vocês. Deus faz muitas coisas em nossa vida e não conseguimos enxergar a grandeza e o propósito de tudo.!!

Pessoas especias surgiram para dividir responsabilidades, sofrer a maratona da coleta de dados; ou simplesmente apoiar, incentivar e confortar, enxugar lágrimas e dividirem gargalhadas. Gostaria de partilhar com estes: Alessandra, Mary, Helenice, Ivy, Elisa Santoro, Angélica, Renatinha e ao Eliseu...pela ajuda memorável e imprescindível, a alegria dessa conquista.!!!

À Secretaria Municipal de Saúde de Jundiaí e Escola Superior de Educação Física (ESEF), pelo apoio no desenvolvimento da pesquisa. Aos funcionários do Departamento de Nutrição e da Comissão de Pós-Graduação pela atenção e colaboração.

À Fundação de Amparo à Pesquisa do Estado de São Paulo (FAPESP) pelos auxílios concedidos. 


\section{Resumo}

Pereira JA. A influência do peso ao nascer sobre a pressão arterial e a composição corporal em crianças. [Dissertação de Mestrado]. São Paulo: Faculdade de Saúde Pública da Universidade de São Paulo; 2007.

Introdução: Estudos epidemiológicos sugerem que a exposição intra-uterina a agravos como desnutrição, hiperglicemia ou hipercortisolemia durante períodos críticos do desenvolvimento leva a alterações metabólicas e endócrinas que persistem na vida adulta, fenômeno denominado de Programação Fetal das Doenças. Objetivos: Avaliar a relação entre peso ao nascer $(\mathrm{PN})$ com os valores atuais de pressão arterial, medidas antropométricas e de composição corporal. Métodos: Estudo de coorte retrospectivo utilizando dados de RONDÓ (2003) em Jundiaí-SP. No seguimento da coorte, avaliouse 472 crianças, atualmente com idade de 5 a 8 anos. Avaliações clínicas consistiram em: medida de pressão arterial (PA), peso (P) e estatura (E) e dosagens bioquímicas: colesterol total (CT), LDL colesterol (LDLc) e HDL colesterol (HDLc) e triglicérides (TG). A composição corporal foi avaliada pela prega cutânea triciptal (PCT) e subescapular (PCS), circunferência braquial (CB) e da cintura (CC), área gordurosa do braço (AGB) e área muscular do braço $(\mathrm{AMB})$ e índice de massa corporal para a idade (IMC). Avaliaram-se as condições socioeconômicas e demográficas em entrevista domiciliar. Para determinação de associação entre variáveis contínuas, utilizou-se o teste de Correlação de Pearson. Para variáveis categóricas, utilizou-se o teste do quiquadrado; e teste " $\mathrm{t}$ " de Student para comparação de médias. Utilizaram-se modelos de regressão linear múltipla para investigar as relações entre as variavéis independentes: PN e comprimento ao nascer $(\mathrm{CN})$ e as variáveis dependentes: $\mathrm{IMC}, \mathrm{CC}, \mathrm{AGB}$, pressão 
arterial sistólica (PAS) e pressão arterial diastólica (PAD), controlando-se os fatores de confusão (sexo, idade, IMC, colesterol total, HDL-c, renda per capita e escolaridade)

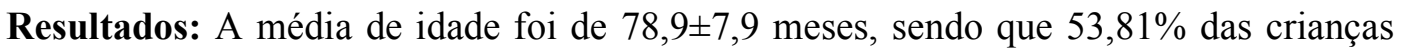
eram do sexo feminino. As prevalências de desnutrição, risco de sobrepeso e de sobrepeso foram de 9,53\%, 14,19\% e 8,47\%, respectivamente. A prevalência de crianças com pressão arterial sistólica $\geq 95$ foi alta $(35,16 \%)$ e a de pressão arterial diastólica $\geq 95$ foi de 5,09\%. Em relação à análise bioquímica, $17,16 \%(n=81)$ das crianças apresentaram HDLc reduzido. Destas, a maior parte $(22,83 \%)$ eram do sexo feminino. O PN mostrou uma correlação positiva com AGB e IMC $(p<0.001)$. As PAS e PAD correlacionaram-se positivamente com IMC e AGB $(p<0.001)$. Na regressão múltipla, ao incluir a variável IMC, observou-se associação inversa significante entre PN e pressão arterial sistólica. Não houve associação significante entre PN e pressão diastólica e entre $\mathrm{CN}$ e PAS e PAD. Conclusões: A relação inversa entre PN com pressão arterial sistólica, a relação direta da pressão arterial com IMC e massas de gordura e muscular e a elevada prevalência de risco de sobrepeso/sobrepeso justificam o controle do estado nutricional de crianças desde o período fetal e a vigilância de medidas da pressão arterial na rotina pediátrica.

Descritores: Peso ao Nascer, Pressão Arterial, Composição Corporal, Comprimento ao Nascer, Crianças. 


\begin{abstract}
Pereira JA. The influence of birth weight on blood pressure and body composition of children. [Master Dissertation] Sao Paulo: School of Public Health, Sao Paulo University; 2007.
\end{abstract}

Introduction: Epidemiological studies suggest that intra-utero exposure to malnutrition, hyperglycemia or hypercortisolemia during critical periods of development leads to metabolic and endocrinological changes that will be expressed in adult life, a condition known as "Fetal Programming". Objectives: To assess the relationship between birth weight (BW) and blood pressure, anthropometric and body composition measurements. Methods: This is a retrospective cohort study based on RONDÓ (2003) data, involving 472 children, aging 5 - 8 years, from Jundiaí, São Paulo. Clinical evaluation included blood pressure (BP), weight (W), height (H) and body mass index (BMI) to age. Body composition: tricipital (TSF) and subscapular skinfold thickness (SSF), mid-upper arm circumference (MUAC), waist circumference (WC), fat mid-upper arm area (FMUAA) and muscle mid-upper arm area (MMUAA). The following elements were determined by biochemical analysis: total cholesterol (TC), LDL-cholesterol (LDLc), HDLcholesterol (HDLc) and triglycerides (TG). Household interview included data about socioeconomic and demographic conditions. In order to check the association among continuous variables, "Pearson correlation test" was performed. "Chi-square" and "tstudent" tests were also performed for categorical variables in order to compare means. Linear regression models were applied to investigate the relationship among independent variables (BW and birth length - BL) and dependent variables (W, S, BMI, WC, FMUAA, systolic blood pressure - SBP and diastolic blood pressure - DBP), controlling for confounders such as gender, age, BMI, total cholesterol, HLD-c, per capita income and escolarity. Results: Mean age was 78,9 \pm 7,9 months; $53,81 \%$ of the children were female. The prevalences of malnutrition, risk of overweight and overweight were $9.53 \%, 14,19 \%$ and $8.47 \%$, respectively. The prevalence of children with a SBP $\geq$ the 95 centile was high (35.16\%) and 5.09\% of the children had a DBP $\geq$ the 95 centile. Eight one (17.16\%) of the children had low HDL-c; from those, $22,83 \%$ 
were female. BW was positively correlated with FMUAA and BMI $(\mathrm{p}<0.001)$. SBP and DBP were positive correlated with BMI and FMUAA $(p<0.001)$. In the final linear regression model, adjusted for BMI, it was noticed a significant inverse relationship between BW and SBP. There were no statistically significant associations between BW and DBP and between BL and systolic and diastolic pressures. Conclusions: The inverse relationship between BW with actual SBP, the straight relationship of BP with fat and muscle mass and BMI, and the high prevalence of the risk of overweight/ overweight, justify the control of the nutritional status of children since the fetal period and the monitoring of BP measurements in the pediatric routine.

Keywords: birth weight, blood pressure, body composition, birth length, children. 


\section{ÍNDICE}

Pág.

\section{INTRODUÇÃO}

1.1. Programação intra-uterina das doenças 19

1.2. A influência do peso ao nascer sobre a pressão arterial 22

1.3. A influência do peso ao nascer sobre a composição corporal 26

2. JUSTIFICATIVA

3. OBJETIVOS

3.1. Objetivo Geral 31

3.2. Objetivos Específicos 31

\section{METODOLOGIA}

4.1. Proposta do estudo principal 33

4.2. O presente estudo 33

4.2.1. Delineamento do Estudo 33

4.2.2. Local do Estudo

4.2.3. Início da Coorte $\quad 37$

4.2.4. População de Estudo 38

4.3. Estágio da Pesquisa $\quad 40$

4.4. Coleta de Dados 41

4.4.1. Treinamento dos Pesquisadores 41

4.4.2. Medidas Antropométricas Atuais 42

4.4.3. Estado Nutricional e Composição Corporal 45

4.4.4. Colheita de Sangue e Dosagens Bioquímicas 46

4.4.5. Medida da Pressão Arterial 47

4.5. Variáveis do Estudo 48

4.6. Análise estatística 49

4.7. Retorno da Informação 51

4.8. Questões Éticas

\section{RESULTADOS}

5.1. Descrição Geral 53 
5.2. Características socioeconômicas e demográficas 56

5.3. Medidas antropométricas e idade gestacional ao nascer 58

5.4. Estado Nutricional 59

5.4.1. Antropometria e composição corporal 59

5.5. Perfil Lipídico da coorte $\quad 62$

5.6. Avaliação da pressão arterial 63

5.7. Relação do peso e comprimento ao nascer sobre a pressão arterial e $\quad 64$ composição corporal atuais

\section{DISCUSSÃO}

6.1. Comentários gerais 76

6.2. Características socioeconômicas e demográficas 78

6.3. Medidas antropométricas e idade gestacional ao nascer 79

6.4. Estado Nutricional 81

6.4.1. Antropometria e composição corporal 81

6.5. Perfil Lipídico da coorte

6.6. Avaliação da pressão arterial 85

6.7. Relação do peso e comprimento ao nascer sobre a pressão arterial e 86 composição corporal atuais

7. CONCLUSÕES 92

8. CONSIDERAÇÕES FINAIS 93

9. REFERÊNCIAS 95

$\begin{array}{ll}\text { 10. ANEXOS } & 109\end{array}$ 


\section{LISTA DE TABELAS}

Pág.

TABELA 1. Comparação de características das crianças incluídas no estudo e das que não concluíram o estudo (perdas).

TABELA 2. Distribuição do número e percentual de variáveis socioeconômicas e demográficas da coorte.

TABELA 3. Distribuição do número e percentual de variáveis estudadas.

TABELA 4. Classificação das crianças, segundo IMC para idade (CDC 2000).

TABELA 5. Valores médios, desvio padrão e intervalos de confiança a $95 \%$ das variáveis antropométricas.

TABELA 6. Valores médios, desvios padrão e intervalos de confiança a $95 \%$ das variáveis de composição corporal.

TABELA 7. Valores médios, desvios padrão (dp) mínimo e máximo e intervalos de confiança das variáveis bioquímicas.

TABELA 8. Distribuição do número, percentual e desvio padrão (DP) da PAS e PAD em percentil, segundo sexo.

TABELA 9. Coeficiente de correlação de Pearson (r) e valores de (p) entre peso ao nascer e as variáveis estudadas.

TABELA 10. Regressão linear da pressão arterial sistólica (PAS). Coeficientes, erros padrão, intervalos de confiança e níveis descritivos do teste.

TABELA 11. Regressão linear da pressão arterial diastólica (PAD). Coeficientes, erros padrão, intervalos de confiança e níveis descritivos do teste.

TABELA 12. Regressão linear da pressão arterial diastólica (PAD). Coeficientes, erros padrão, intervalos de confiança e níveis descritivos do teste.

TABELA 13. Regressão linear da área de gordura do braço (AGB). Coeficientes, erros padrão, intervalos de confiança e níveis descritivos do teste.

TABELA 14. Regressão linear da circunferência da cintura (CC). Coeficientes, erros padrão, intervalos de confiança e níveis descritivos do teste.

TABELA 15. Regressão linear do índice de massa corpórea (IMC). Coeficientes, erros padrão, intervalos de confiança e níveis descritivos do teste. 


\section{Lista DE FIGURAS}

Pág.

35

FIGURA 1. Mapa mostrando as cidades que fazem fronteira com o município de

Jundiaí - SP.

FIGURA 2. Mapa mostrando os bairros do município de Jundiaí - SP.

FIGURA 3. Seguimento da coorte em Jundiaí - SP.

FIGURA 4. Distribuição numérica e percentual das crianças convocadas para o seguimento da coorte.

FIGURA 5. Regressão linear da pressão arterial sistólica - PAS, segundo peso ao nascer.

FIGURA 6. Regressão linear da pressão arterial diastólica - PAD, segundo peso ao nascer.

FIGURA 7. Regressão linear do índice de massa corpórea - IMC, segundo peso ao nascer. 


\section{Lista DE Siglas E ABREVIATURAS}

PN - peso ao nascer

$\mathrm{CN}$ - comprimento ao nascer

RCIU - restrição do crescimento intra-uterino

DCNT - doenças crônicas não transmissíveis

PA - pressão arterial

PAS - pressão arterial sistólica

PAD - pressão arterial diastólica

HA - hipertensão arterial

CT - colesterol total

LDLc - lipoproteina de baixa densidade (colesterol LDL)

HDLc - lipoproteína de alta densidade (colesterol HDL)

TG - triglicérides

PCT - prega cutânea tricipital

PCS - prega cutãnea subscapular

$\mathbf{P}$ - peso

E - estatura

CB - circunferencia do braço

CC - circunferência da cintura

AGB - área de gordura do braço

AMB - área muscular do braço

IMC - índice de massa corpórea

RCQ - relação cintura/quadril

11-ß3-HSD - 11-ß3-hidroxiesteróide desidrogenase placentária

$Z P I$ - escore $Z$ peso para idade

ZEI - escore $Z$ estatura para idade

IG - idade gestacional

PIG - pequeno para idade gestacional

GIG - grande para idade gestacional

DUM - data da última menstruação

SM - salário mínimo

IC-95\% - intervalo de confiança de $95 \%$

dp - desvio padrão

ANOVA - análise de variância

$\mathbf{R}^{2}$ - coeficiente de determinação

HIV - Human Imunnedeficiency Virus

ENDEF - Estudo Nacional de Despesa Familiar

PNSN - Plano Nacional de Saúde e Nutrição

CDC - Center for Disease Control and Prevention

OMS - Organização Mundial de Saúde

IBGE - Instituto Brasileiro de Geografia e Estatística 
INTRODUÇÃO 


\subsection{INTRODUÇÃO}

\subsection{Programação intra-uterina das doenças}

Estudos epidemiológicos realizados na década de 90 demonstraram associações estatísticas relevantes entre a desnutrição intra-uterina e o desenvolvimento de doenças crônicas que aparecem principalmente na idade adulta. Estes achados são provenientes de pesquisas que observaram inicialmente uma forte associação geográfica entre mortalidade por doença cardiovascular em adultos e mortalidade infantil (BARKER et al 1989).

Com base em séries de coortes históricas e extrapolando resultados de estudos em animais, BARKER (1990) propôs que a doença crônica seria biologicamente programada no útero ou no início do primeiro ano de vida e denominou "programming" o processo em que o estímulo ou a agressão, em períodos críticos do desenvolvimento, teria repercussão na estrutura ou na função de órgãos, tecidos e sistemas orgânicos. Para doenças coronarianas, por exemplo, a hipótese sugerida é de que a desnutrição fetal na metade ou no final da gestação estaria relacionada com elevação da pressão arterial, alterações da coagulação sanguínea e do metabolismo do colesterol.

Também foi proposta por HALES \& BARKER (1992) uma teoria, denominada origem fetal das doenças ou hipótese do fenótipo econômico. Esta sugere que indivíduos expostos à nutrição deficiente no útero e nos primeiros anos de vida desenvolvem um mecanismo de adaptação com redução do número e da atividade das 
células beta do pâncreas e prejuízo dos tecidos insulino-dependentes, principalmente os músculos.

Segundo Yajnik (2000), a condição adversa provavelmente mais comum para o feto é a desnutrição, sendo que em períodos de escassez, a sobrevivência deste é conseguida por uma redução da taxa de crescimento. De acordo com a fase da gestação em que ocorreu este prejuízo, diversos sistemas serão afetados, com diferentes impactos para a vida futura como hipertensão arterial, dislipidemias e obesidade.

O indivíduo que desenvolveu desnutrição intra-uterina adapta-se para sobreviver com aporte energético reduzido. Se ao longo da vida, estes indivíduos receberem quantidades elevadas de nutrientes, associada à redução do nível de atividade física, esta adaptação poderá se tornar evidente, dando origem a um descontrole metabólico, com redução da sensibilidade à insulina, obesidade, diabetes tipo 2 e hipertensão arterial (ROSENBLOOM 2002).

A principal estratégia de adaptação do feto à nutrição deficiente é a redistribuição seletiva de nutrientes para formação de órgãos fundamentais como o cérebro (brain-sparing). Este mecanismo resultaria em subdesenvolvimento do esqueleto, fígado, menor proporção de massa muscular, redução da massa de células beta do pâncreas e anormalidades no tecido vascular (KRENTZ 2002).

A desnutrição pré-natal tem sido o modelo mais extensamente avaliado de programação fetal de doenças cardiovasculares, em especial a hipertensão arterial (EDWARDS et al 2001, LANGLEY-EVANS 2001). De acordo com esses autores, alterações no estado nutricional materno, refletidas no peso ao nascer, bem como a exposição fetal à glicocorticóides, seriam a base para o desenvolvimento de hipertensão arterial e aterosclerose na idade adulta. 
Dessa forma, ressalta-se a importância de avaliar o peso ao nascer (PN) que reflete as condições nutricionais do recém-nascido e da gestante, sendo considerado indicador apropriado de saúde individual (WHO 2002). Além disso, o PN reflete também características biológicas do recém-nascido, além de condições socioeconômicas e qualidade da atenção à saúde pré-natal (MENESES et al 1998, MORAIS \& BARROS 2000).

BARKER et al 1993 observou que o crescimento e o desenvolvimento pósnatal da criança são influenciados pelo PN e repercute nas condições de saúde do adulto. Sendo assim, o estudo do PN é importante, pois seus extremos, peso baixo e excesso de peso, podem acarretar conseqüências à saúde do indivíduo no período neonatal, durante a infância e na idade adulta (BERNABÉ et al 2004).

Outro importante processo patológico capaz de modificar o potencial de crescimento fetal chama-se restrição de crescimento intra-uterino - RCIU. Os principais determinantes do RCIU em países em desenvolvimento são: consumo insuficiente de energia durante a gestação com conseqüente ganho insuficiente de peso gestacional, baixo índice de massa corporal (IMC) pré-gestacional, baixa estatura materna, primiparidade, hipertensão induzida pela gestação e tabagismo (KRAMER 2003).

Estudos demonstram que, recém-nascidos de pesos mais baixos ao nascer sejam por prematuridade ou por RCIU aparentemente apresentam maior prevalência de doença cardiovascular, hipertensão arterial sistêmica, aterosclerose e intolerância à glicose e síndrome metabólica (de ONIS et al 1998).

Para estudar a relação do peso ao nascer com a elevação da pressão arterial na infância, adolescência e idade adulta, as pesquisas investigam preferencialmente o 
PN como variável contínua (YAJNIK 2002, BARKER et al 1993) onde a maior parte delas suporta a idéia de baixos pesos ao nascimento estarem associados a aumento de riscos cardiovasculares, inclusive aumento dos níveis pressóricos.

MESHARI et al (1990) mostraram que além de baixos pesos ao nascer, a macrossomia ou obesidade fetal (peso ao nascer maior do que o percentil 90 para a idade gestacional ou peso ao nascimento $>4 \mathrm{~kg}$, independente da idade gestacional ou sexo) está relacionada a alterações no metabolismo dos carboidratos e lipídeos que podem persistir após o nascimento.

A macrossomia fetal está associada ao desenvolvimento tardio de obesidade, diabetes e dislipidemia (PRIBYLOVA \& DVORAKOVA 1996). Estas observações são concordantes com a associação epidemiológica descrita por Barker entre os níveis lipídicos fetais e o risco de doença cardiovascular (BARKER 2000).

\subsection{A influência do peso ao nascer sobre a pressão arterial}

A hipertensão arterial (HA) representa um dos principais problemas de saúde pública, tanto nos países desenvolvidos como em desenvolvimento, apresenta elevado custo médico-social e caracteriza-se como um importante fator de risco independente, linear e contínuo para doença cardiovascular. (LEWINGTON et al 2002). É responsável por $25 \%$ a $40 \%$ da etiologia multifatorial das doenças isquêmicas cardíacas e dos acidentes vasculares cerebrais, respectivamente. Esta multiplicidade de conseqüências coloca a hipertensão arterial na origem das doenças 
crônico-degenerativas e, portanto, a caracteriza como uma das causas de maior redução da qualidade e expectativa de vida dos indivíduos (FUCHS 2004).

Não existem dados populacionais da prevalência da hipertensão no país. Estima-se, com base em dados obtidos em alguns estudos de base populacional, que ela afete aproximadamente um quarto da população adulta brasileira. Desta maneira, atividades de vigilância em relação à hipertensão são de grande importância para a saúde pública (SOCIEDADE BRASILEIRA DE HIPERTENSÃO - SBH 2006).

Estudos mostram que pesos baixos ao nascer expõem adultos ao maior risco de desenvolverem HA, doença pulmonar obstrutiva e lesões renais e apresentarem elevadas concentrações de colesterol. A predisposição dos indivíduos a estes diferentes agravos dependerá do período gestacional em que ocorreu o comprometimento nutricional e o tipo de desnutrição intra-uterina (GODFREY \& BARKER 2000).

Das doenças do adulto associadas com o PN, a HA é a mais estudada. Aproximadamente 80 estudos envolvendo mais de 444.000 indivíduos em várias partes do mundo suportam a relação inversa entre PN e PA sistólica em adulto, adolescentes e crianças (HUXLEY et al 2000). Estes achados têm implicações para a atuação dos profissionais de saúde na prevenção de eventos cardiovasculares, pois tem sido demonstrado que a pressão elevada na infância pode ser fator preditivo de HA sistêmica na vida adulta. Estudos de coorte encontraram uma significativa correlação entre pressão arterial em crianças e adolescentes e hipertensão na idade adulta (DANIELS 2000).

MAHONEY (1991) afirma que crianças com pressão arterial acima do percentil 90 têm risco 2,4 vezes maior de serem adultos hipertensos. A HA em crianças não se apresenta como fator de risco para eventos cardiovasculares na infância. No 
entanto, observam-se alterações cardiovasculares e hemodinâmicas nesses indivíduos a partir da segunda década de vida ou mesmo mais precocemente (DANIELS 2002).

A elevação da PA tem sido relacionada com desordens do crescimento fetal desde a década de 80, quando WADSWORTH (1985) publicou um estudo com pessoas nascidas na Inglaterra em 1946 e examinadas 36 anos depois, verificando que indivíduos com PN mais baixos tiveram PA sistólica mais elevada. Em estudos subseqüentes, este resultado confirmou-se: o aumento no peso ao nascer esteve associado com queda da PA (LAUNER et al 1995, NILSSON 1997).

ROSE G (1985) mostrou em seu estudo uma redução de $3,5 \mathrm{mmHg}$ na PA com o aumento de $1 \mathrm{~kg}$ no PN. Neste trabalho, o autor sugere que reduzir a PA sistólica média de uma população em $10 \mathrm{mmHg}$ poderia corresponder a $30 \%$ de redução na mortalidade total. HUXLEY et al. (2000) também observaram que, a cada $1 \mathrm{~kg}$ de elevação no PN, há redução de 2 a 3 mmHg e 2 a 4 mmHg na PA sistólica em crianças e adultos, respectivamente. Embora tal redução não pareça significante no âmbito individual, pode representar uma diferença significativa em nível populacional. Estudos mostram que, reduzindo a PA sistólica média de uma população em $10 \mathrm{mmHg}$, reduziríamos a taxa de mortalidade total em 30\% (ADABAG 2001).

Um mecanismo que relaciona o PN e a elevação da PA refere-se às mudanças na estrutura vascular, incluindo perda da elasticidade da parede dos vasos e os efeitos dos hormônios glicocorticóides (BARKER 1998, BENEDIKTSSON 1993). Os glicocorticóides são reguladores da expressão de uma série de genes e a ativação inadequada de determinados genes durante períodos críticos podem determinar alterações adversas no desenvolvimento fetal.

Em condições normais, o feto é protegido da exposição ao corticóide materno pela ação da enzima denominada de 11-ß-hidroxiesteróide desidrogenase (11-ß-HSD) 
placentária, que converte o cortisol em metabólitos inativos (cortisona). Essa proteção prevalece até o final da gestação, quando a função supra-renal do feto é ativada e dá origem ao eixo hipotálamo-hipófise-supra-renal (SECKL 1995). A exposição fetal aos glicocorticóides pode também alterar a função do eixo hipotálamo hipófise-supra-renal. Em experimentos com ratos, um aumento de sensibilidade aos corticóides resulta do aumento da atividade dos receptores desse eixo (WALKER et al 1996).

O papel do rim como mediador do desenvolvimento de hipertensão arterial programada foi sugerido a partir da observação de alterações estruturais e funcionais. No que diz respeito à estrutura renal, a alteração mais consistentemente encontrada refere-se à diminuição do número de néfrons, considerando-se que o número de néfrons já está determinado com 36 semanas de gestação. A diminuição do número de néfrons parece estar relacionada ao tamanho dos rins. Crianças que tiveram crescimento intrauterino retardado têm rins pequenos e com menor número de néfrons (HINCHLIFFE 1992, SCHREUDER \& NAUTA 2007).

LAUNER et al (1993) em estudo realizado na Holanda, mostraram que entre bebês menores houve um aumento relativo na PA no início da infância, o que poderia está relacionado com uma "programação" da pressão em níveis mais elevados. Este mesmo estudo encontrou também um padrão alterado de PA em indivíduos que nasceram com peso mais elevado, estabelecendo uma curva em U. 


\subsection{A influência do peso ao nascer sobre a composição corporal}

LAW (2002) afirma que não há número suficiente de estudos publicados descrevendo o impacto do PN na PA e perfil lipídico durante a infância. Observou-se também que a maioria dos estudos disponíveis foram realizados principalmente em países com alto índice de desnutrição como é o caso da Índia e de países da África ou em regiões desenvolvidas como Estados Unidos e Europa.

A associação descrita entre obesidade e dislipidemia em adultos também tem sido descrita em crianças e adolescentes. O "Bogalusa Heart Study" verificou que escolares com excesso de peso tinham um risco 2,4 a 7,1 vezes maiores de apresentarem colesterol, LDLc e triglicérides elevados, quando comparados com crianças sem excesso de peso (FREEDMAN et al 1999).

SARNI et al (2005) encontrou em seu estudo, diferença estatisticamente significante entre as médias do escore $\mathrm{z}$ de peso para idade (ZPI) e de escore $\mathrm{z}$ de estatura para a idade (ZEI) para crianças com baixo peso $(<2500 \mathrm{~kg})$ e peso inadequado ao nascer $(2500$ - $2999 \mathrm{~kg})$. Em relação à massa magra do braço, houve uma forte tendência para que as crianças com peso adequado ao nascimento apresentassem maior média de massa muscular quando comparadas com crianças com baixo peso ao nascer.

Nas crianças, as alterações nutricionais e o surgimento de fatores de risco para doenças cardiovasculares ainda representam um desafio para a saúde pública nos países em desenvolvimento. A identificação dessas alterações possibilita a adoção de medidas preventivas e curativas mais adequadas. Os resultados deste estudo poderão contribuir para a adoção de intervenções específicas que melhorem a qualidade da atenção à saúde 
pré-natal e consequentemente reduzam os distúrbios nutricionais e o surgimento de doenças crônico-degenerativas na idade adulta.

O presente estudo foi desenvolvido por pesquisadores da Faculdade de Saúde Pública, entre os anos de 2005 e 2007, um estudo de coorte prospectiva que avaliou crianças nascidas entre 1997 e 2000 em Jundiaí, São Paulo, filhos de mães que participaram do estudo de RONDÓ (2003). A partir dos dados anteriores e de outros coletados no presente, pode-se investigar a influência do peso ao nascer sobre a pressão arterial e composição corporal destas crianças.

Conta-se com banco de dados de peso ao nascer bem como outras medidas antropométricas importantes e nem sempre disponíveis em alguns estudos acima descritos, rigidamente coletados. Vale ressaltar que grande parte das pesquisas utiliza-se de dados secundários de registros de nascimentos, ao contrário deste. Considerando-se que as medidas foram obtidas pela pesquisadora principal, por meio de financiamento da FAPESP (processo no 1998/00321-0). 
JUSTIFICATIVA 


\subsection{JUSTIFICATIVA}

Considerando-se que os primeiros estudos de Barker foram publicados na década de 80, ainda é pouco investigada a Teoria da Origem Fetal das Doenças, nos países em desenvolvimento, com exceção da Índia, onde esse assunto está sendo mais pesquisado.

Ressalta-se que o perfil de saúde da população brasileira apresenta características complexas, devido ao período de transição epidemiológica, demográfica e nutricional. Observa-se que nas últimas décadas houve um predomínio das doenças crônicas não-transmissíveis, em detrimento das doenças infecciosas, parasitárias e desnutrição.

A identificação precoce de fatores de risco para o desenvolvimento das doenças crônicas é de fundamental importância. Estudos indicam que o processo aterosclerótico começa a se desenvolver na infância, progredindo significativamente na terceira e quarta década de vida.

Assim, julgou-se pertinente realizar um estudo de coorte, de abordagem prospectiva, para verificar a relação do peso ao nascer com os valores de pressão arterial e de composição corporal em crianças de 5 a 8 anos de idade, a fim de eventualmente poder auxiliar, com mais elementos, na compreensão do processo saúde-doença e atuar na prevenção e controle das doenças crônicas não transmissíveis que possam ter início na infância. 
OBJETIVOS 


\section{OBJETIVOS}

\subsection{Geral}

Estudar a relação entre peso ao nascer e os valores de pressão arterial e da composição corporal atuais na coorte de crianças de Jundiaí - SP.

\subsection{Específicos}

- Descrever a população estudada de acordo com as características sócioeconômico-demográficas, estado nutricional e perfil lipídico;

- Verificar a relação entre PN e valores de pressão arterial atuais;

- Verificar a relação entre PN e composição corporal atuais. 
$\underline{\text { MeTODOLOGIA }}$ 


\subsection{METODOLOGIA}

\subsection{Proposta do estudo principal}

Este estudo está inserido no projeto principal intitulado "Efeito do peso ao nascimento no desenvolvimento de resistência à insulina, obesidade e alteração da pressão arterial em crianças de 5-8 anos no município de Jundiai - SP”, que tem por objetivo avaliar a relação do peso ao nascer no desenvolvimento de doenças crônicas em crianças, descrevendo o perfil lipídico, glicêmico, insulínico, valores de pressão arterial e medidas de composição corporal.

O projeto foi financiado pela agência Fundação de Amparo à Pesquisa do Estado de São Paulo - projeto FAPESP n. ${ }^{\circ}$ 04/04109-8.

\subsection{O presente estudo}

\subsubsection{Delineamento do estudo}

Essa dissertação de mestrado é um estudo epidemiológico, de coorte prospectiva, do nascimento até a idade de 5 a 8 anos, das crianças que compuseram a coorte original de Rondó entre 1997 e 2000, e atualmente envolveu três fases de coleta de dados. 


\subsubsection{Local do estudo}

O estudo foi realizado no município de Jundiaí, cidade do estado de São Paulo, região sudeste do Brasil. Jundiaí está localizada a $63 \mathrm{~km}$ da capital do estado de São Paulo e possui aproximadamente 345 mil habitantes, distribuídos em uma área de 432

$\mathrm{km}^{2}$, sendo $112 \mathrm{~km}^{2}$ área urbana e 228,6 $\mathrm{km}^{2}$ área rural, tendo como principais produtos agrícolas a uva, o morango e o pêssego.

$\mathrm{O}$ acesso à cidade é feito pelas rodovias Anhanguera, Bandeirantes e Dom Gabriel Paulino Couto. O Município faz limite com 11 municípios: Várzea Paulista, Campo Limpo Paulista, Franco da Rocha, Cajamar, Pirapora do Bom Jesus, Cabreúva, Itupeva, Louveira, Vinhedo, Itatiba e Jarinú (IBGE, 2005). 
FIGURA 1. MAPA MOSTRANDO AS 11 CIDADES QUE FAZEM FRONTEIRA COM O MUNICÍPIO DE JUNDIAÍ.

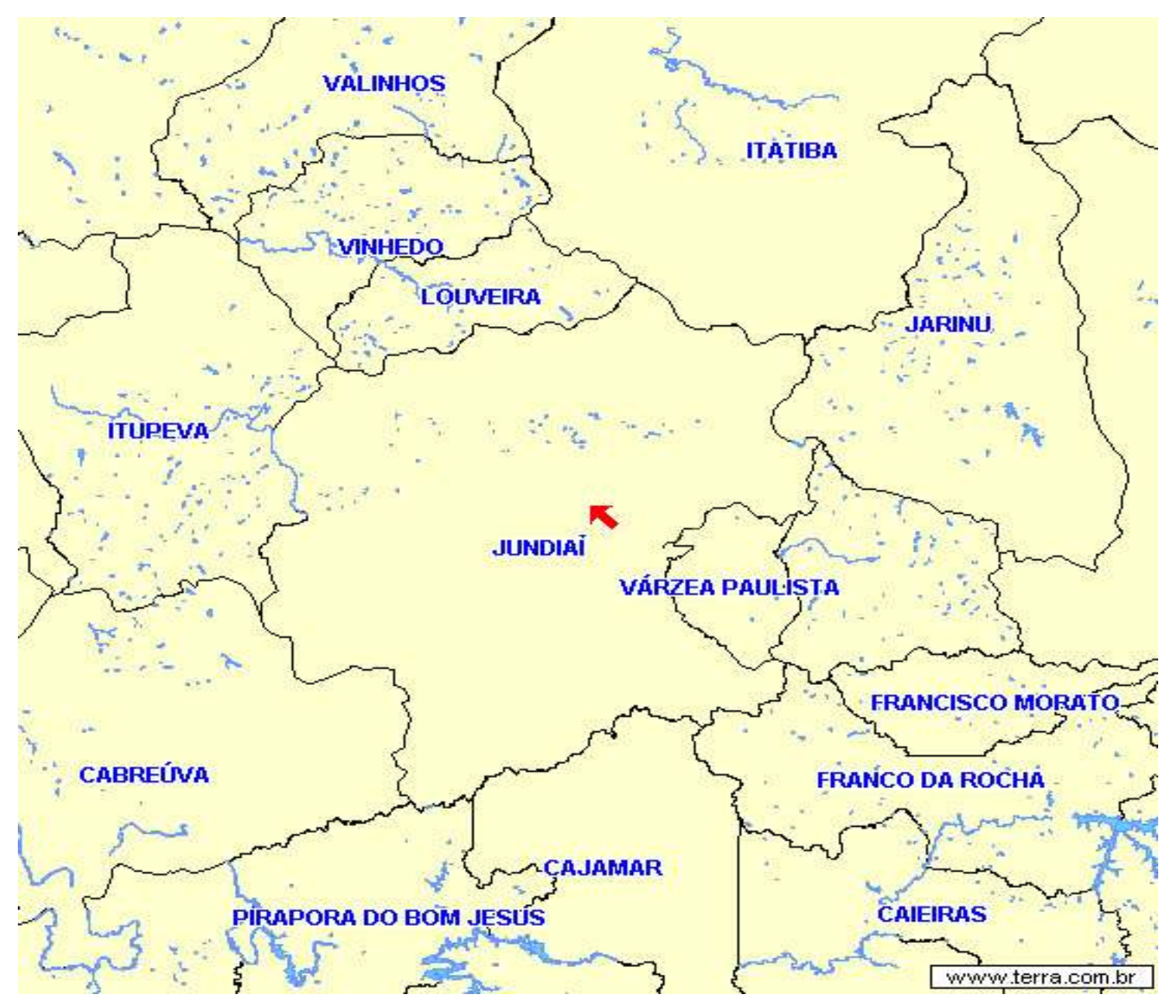


FIGURA 2. MAPA MOSTRANDO OS BAIRROS DO MUNICÍPIO DE JUNDIAÍ.

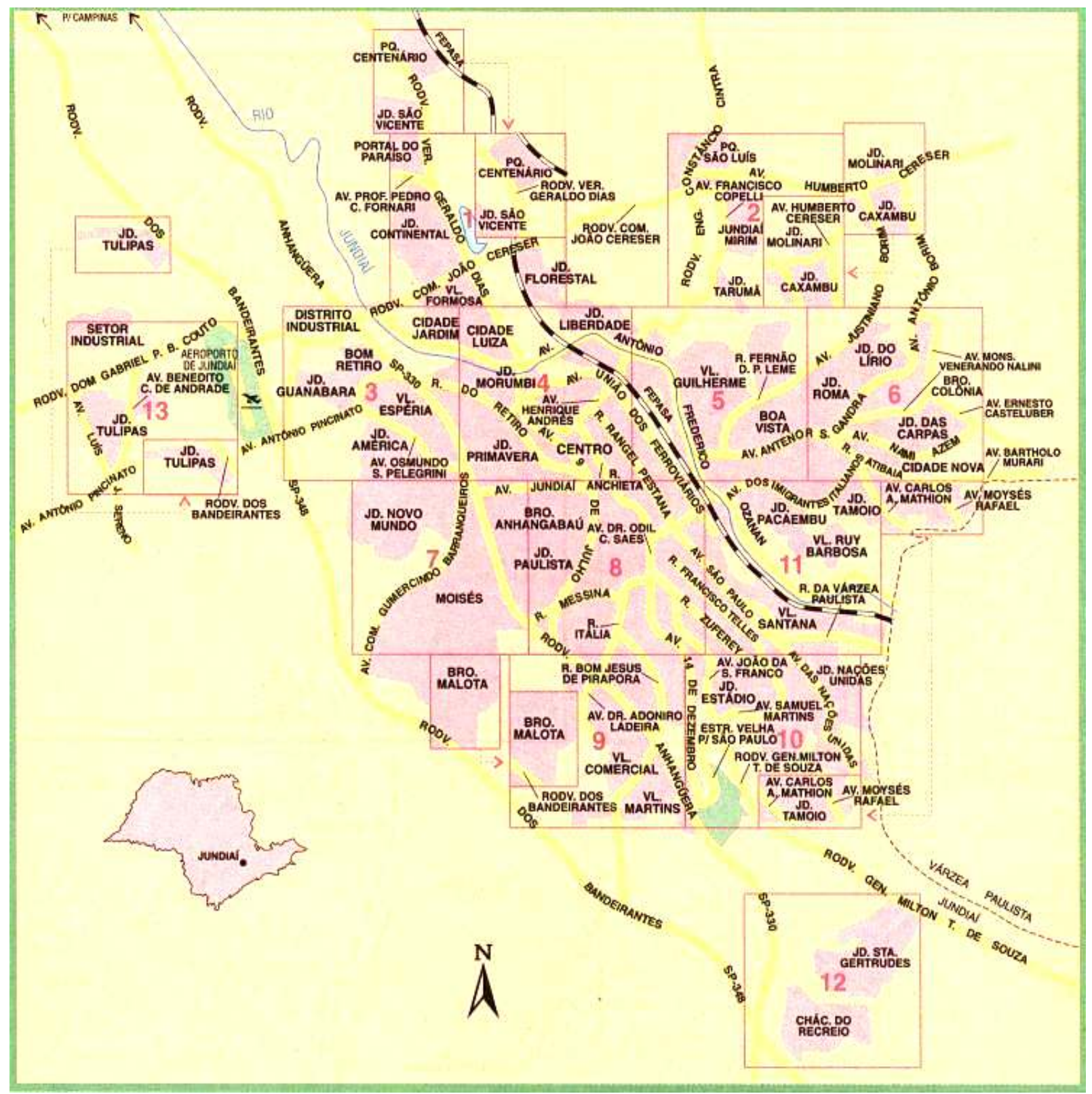




\subsubsection{Início da Coorte}

A coorte foi inicialmente formada por 890 crianças nascidas entre 1997 e 2000 no município de Jundiaí - SP, em hospitais conveniados ao Sistema Único de Saúde (SUS).

As mães inicialmente incluídas no estudo foram selecionadas desde que não houvesse gravidez de risco e foram acompanhadas em três momentos: do período de realização dos exames pré-natais até o nascimento da criança.

A pesquisadora informava-se da data de nascimento da criança para que fosse devidamente coletado o peso, comprimento e outras variáveis da criança ao nascer com a devida cautela.

O peso ao nascer foi aferido utilizando balanças do próprio hospital em que nasceram as crianças. A equipe da pesquisa tinha o cuidado de diariamente conferir os equipamentos a serem utilizados para reduzir os erros de medida e a criança era pesada e medida até 48 horas após o nascimento.

Nesse estudo de Rondó (2003), considerou-se a idade gestacional baseada na data da última menstruação da parturiente (DUM). Posteriormente, entre 12 e 48 horas após o nascimento, todos os recém-nascidos tiveram a idade gestacional (IG) avaliada pelo método proposto por CAPURRO et al (1978). Este método baseia-se na avaliação de 7 parâmetros (5 somáticos e 2 neurológicos), atribuindo pontos para cada item analisado. 


\subsubsection{População de Estudo}

Para o presente estudo, das 890 mães e crianças que compuseram a coorte inicial, 745 foram localizadas e convidadas a participar dessa coorte prospectiva, resultando em uma amostra final de 649 crianças de 5 a 8 anos de idade, cujos pais assinaram o Termo de Consentimento e responderam o questionário socioeconômico, conforme mostra a Figura 3.

FIGURA 3 - SEGUIMENTO DA COORTE EM JUNDIAÍ.

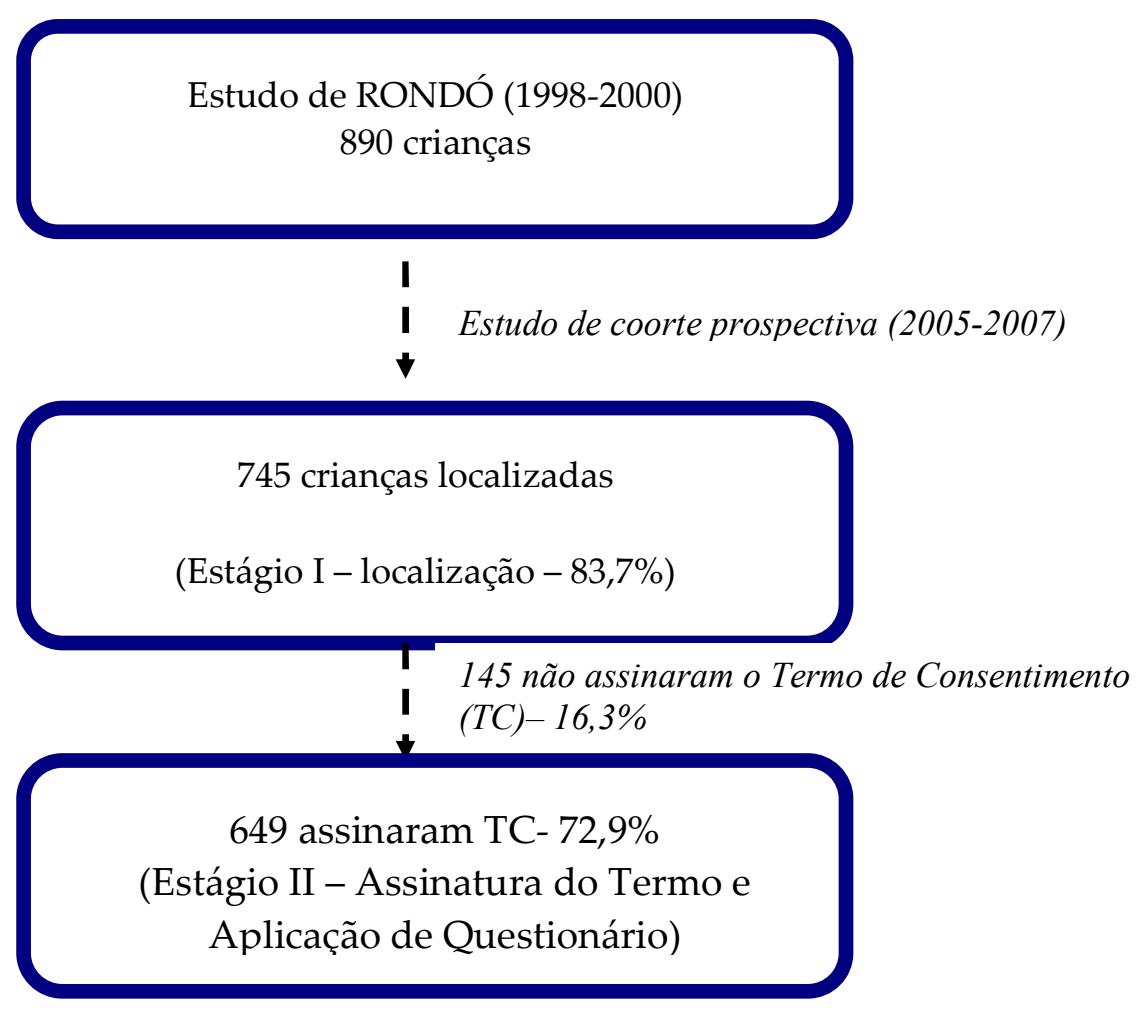




\subsection{Estágios da Pesquisa}

A coleta de dados deste estudo iniciou-se em novembro de 2004 e terminou em setembro de 2006. Foi realizada em três estágios:

\section{- Estagio 1}

A partir de dados obtidos por meio de questionário da pesquisa original, foi efetuado um processo de localização das mães, que na época do estudo original de RONDÓ (2003) residiam em Jundiaí e cidades próximas.

Para a atualização de endereços e telefones, foi utilizado o sistema de cadastro dos hospitais do município, da Secretaria Municipal de Saúde, da Secretaria Municipal de Educação, das escolas municipais e da Fundação Municipal de Assistência Social FUMAS.

O convite para as mães participarem do estudo atual foi por contato telefônico, quando possível. Agendava-se uma entrevista em domicílio, onde, nessa ocasião, realizava-se o esclarecimento a respeito da pesquisa, com solicitação de consentimento formal, através da assinatura do Termo de Consentimento.

A inclusão da criança na pesquisa só ocorreu quando o responsável aceitou participar do estudo, mediante assinatura de Carta de Consentimento. Nessa visita domiciliar, realizou-se também, um questionário para mensuração das características sócio-econômicas. 


\section{Estagio 2}

Após o primeiro contato, marcou-se por telefone o dia, local e horário para realização da coleta de:

1. Medidas antropométricas: peso, estatura, circunferências da cintura, tórax, e braquial, pregas cutâneas do tríceps e subescapular.

2. Amostras de sangue para dosagens de colesterol total, HDL-colesterol, LDL-colesterol e triglicérides.

\section{- Estagio 3}

Nessa etapa, realizou-se a avaliação da pressão arterial das crianças, por intermédio de um aparelho denominado CV PROFALOR ${ }^{\circledR}$, mais informações do aparelho estão disponíveis em: $\underline{\text { www.hdii.com/research.htm. }}$ O exame foi realizado em uma Clínica de Cardiologia, na cidade de Jundiaí.

\subsection{Coleta de Dados}

\subsubsection{Treinamento dos Pesquisadores}

Foram realizados dois treinamentos para pesquisadores de campo para coleta de dados. O primeiro treinamento foi para a aplicação correta do questionário sócioeconômico. O segundo treinamento foi para padronizar os métodos da avaliação antropométrica e foi realizado no Laboratório de Avaliação Nutricional de Populações 
(LANPOP) do Departamento de Nutrição da Faculdade de Saúde Pública da USP. Participaram da coleta de dados das medidas antropométricas avaliadores treinados, com padronização dos procedimentos da coleta dos dados.

\subsubsection{Medidas antropométricas atuais}

As medidas antropométricas foram determinadas por meio de instrumentos

padronizados na Escola Superior de Educação Física - ESEF, a qual possui localização central no município. As medidas foram realizadas em triplicatas.

\section{- Peso e Altura}

O peso corporal foi avaliado com uma balança eletrônica portátil, marca Soehnle, precisão de $10 \mathrm{~g}$. As crianças foram pesadas sem roupas em posição vertical e foram mantidas no centro da balança. A altura era aferida com um antropômetro fixo à parede, marca SECA, precisão de $0,1 \mathrm{~cm}$. As crianças foram medidas sem sapatos, com os pés juntos e com os calcanhares, região glútea e ombros encostados a uma superfície vertical. A cabeça foi posicionada no plano de "Frankfurt" (com a linha de visão perpendicular ao corpo) e com os braços relaxados. (WHO 1995, HEYWARD \& STOLARCZK 2000). 


\section{- Circunferências Corporais: cintura e braço}

Para as médias das circunferências, foi utilizada fita métrica, não extensível, com as crianças em pé, sem roupa, na posição vertical, com os braços posicionados ao longo do corpo e na fase expiratória da respiração. A mensuração foi feita com pressão suficiente para que a fita métrica ficasse totalmente aderida ao corpo no local referido, sem ficar muito frouxa ou apertada demais.

A circunferência da cintura foi feita com a fita circundando o indivíduo na linha natural da cintura, na região mais estreita entre o tórax e o quadril, no ponto médio entre a margem inferior da última costela e a crista ilíaca no plano horizontal. A leitura foi realizada no momento da expiração.

Para obtenção da circunferência braquial o braço avaliado foi flexionado em direção ao tórax, formando um ângulo de $90^{\circ}$ graus. A partir daí, localizou-se e marcou o ponto médio entre o processo acromial e o olécrano na posição vertical. Solicitou-se ao individuo pra ficar com o braço estendido ao longo do corpo e a palma da mão voltada para coxa. Em seguida, contornou-se o braço com a fita flexível no ponto marcado para verificar o valor obtido. (WHO 1995, HEYWARD \& STOLARCZK 2000).

\section{- Pregas Cutâneas}

A medida das pregas cutâneas é realizada com adipômetro marca Lange ${ }^{\circledR}$, precisão $0,1 \mathrm{~mm}$. As instruções gerais seguidas para aferição das pregas foram: 
- Identificar e marcar o local a ser medido

- Segurar a prega formada pela pele e pelo tecido adiposo com os dedos polegar e indicador da mão esquerda a $1 \mathrm{~cm}$ do ponto marcado.

- Pinçar a prega com o calibrador exatamente no local marcado.

- Manter a prega entre os dedos até o término da aferição.

- A leitura será realizada no milímetro mais próximo em cerca de dois a três segundos.

- Utilizar a média de três medidas.

A avaliação das pregas cutâneas foi realizada com cuidado para reduzir a variabilidade inter e intra-avaliador. Esta fonte de erro foi minimizada por meio de padronização dos procedimentos e treinamento das técnicas de avaliação.

\section{- Prega cutânea tricipital (PCT)}

A prega tricipital foi aferida com a criança em pé, com o braço dominante estendido e relaxado livremente ao longo do corpo. Mediu-se a distância entre o processo acromial da escápula e o olécrano na ulna, marcando-se o ponto médio entre essa distância. A pele e o tecido subcutâneo nesse ponto médio foram pinçados, inicialmente com a ponta dos dedos, e, em seguida, com a ponta do adipômetro. 


\section{- Prega cutânea subescapular (PCSE)}

A prega cutânea subescapular foi obtida com o avaliado na posição em pé, ombro relaxado, dobra cutânea localizada obliquamente ao eixo longitudinal do corpo, na orientação dos arcos costais, dois centímetros do ângulo inferior da escápula.

Todas as medidas, incluindo-se as circunferências, foram realizadas segundo a técnica de CAMERON (1984) e JELLIFE (1989).

\subsubsection{Estado nutricional e composição corporal}

O estado nutricional foi avaliado por meio do cálculo do IMC (peso (kg) /altura $\left.\left(\mathrm{m}^{2}\right)\right)$ das crianças, seguindo classificação proposta por CDC (2000), que propõe a denominação risco de sobrepeso quando o IMC para a idade for $\geq$ ao percentil 85 e $\leq$ que o percentil 95 da curva de referência; e sobrepeso quando a criança apresenta IMC para a idade $\geq$ ao valor do IMC no percentil 95 da curva de referência. O CDC não classifica obesidade com base no IMC, uma vez que este índice é inexato para medir gordura corporal (anexo V).

As medidas de composição corporal derivadas foram estimadas a partir dos valores de espessura das pregas cutâneas determinadas na região tricipital e circunferência do braço, usando as equações propostas por FRISANCHO 1990. No entanto, apenas a variável AGB (área de gordura do braço) foi utilizada na análise estatística. 


\subsubsection{Colheita de sangue e Dosagens bioquímicas}

Amostras de sangue para as determinações do perfil lipídico foram colhidas de criança em jejum de 10 - 12 horas, no início da manhã, por punção venosa periférica utilizando-se agulhas e seringas descartáveis.

O sangue foi distribuído em 3 tubos, os quais foram identificados com etiquetas contendo o número e nome completo da criança e data da colheita. Após a retração do coágulo o soro foi separado por centrifugação a $1500 \mathrm{rpm}$ por 10 minutos (Centrífuga TOMY, modelo IC-15AN, Tominaga Works LTD, Tókio, Japão) durante 10 minutos e armazenadas em geladeira a $0^{\circ} \mathrm{C}$ por um período de $24-48$ horas. Em seguida foram transportadas para o Laboratório do Hospital Universitário - HU/USP, onde foram realizadas as determinações bioquímicas.

Vale ressaltar que, anteriormente à colheita foi encaminhada semanalmente para o HU/USP, uma lista com o número da criança, nome completo e data de nascimento para que fossem gerados o código e senha de acesso ao resultado de cada criança.

O colesterol total foi analisado por meio de método enzimático calorimétrico (colesterol oxidase automatizado), utilizando-se o aparelho Advia 1650. Para análise do HDLc, utilizou-se o mesmo aparelho e método acima descrito, logo após precipitação das lipoproteínas de baixa densidade. O LDLc é obtido através da fórmula de FREIDEWALD (1972): 
$L D L$-colesterol $=$ colesterol total $-($ VLDL-colesterol $+H D L$-colesterol $)$

Sendo VLDL-colesterol $=$ triglicérides $/ 5$

Os triglicerídeos foram medidos fotometricamente após reação enzimática (glicerol peroxidase automatizado).

$\mathrm{O}$ anexo $\mathrm{V}$ mostra a classificação do colesterol total e frações e dos triglicérides, realizado de acordo as recomendações da Sociedade Brasileira de Cardiologia - I Diretriz de Prevenção da Aterosclerose na infância e na adolescência (2005).

\subsubsection{Medida da Pressão Arterial}

Obteve-se uma única medida de PA, por intermédio de um aparelho denominado HDI/Pulse Wave ${ }^{\mathrm{TM}}$ CR 2000 - Cardiovascular Profalor ${ }^{\circledR}$, sistema não invasivo, capaz de medir parâmetros hemodinâmicos, inclusive a complacência das artérias e é capaz de medir precocemente as alterações de pequenos e grandes vasos e avaliar o início da doença vascular (http//www.hdii.com/research.htm).

O HDI/Pulse Wave ${ }^{\mathrm{TM}}$ CR 2000 - Cardiovascular Profalor ${ }^{\circledR}$ foi projetado para pesquisas científicas e uso clínico. Fornece informações correlacionadas a 15 parâmetros cardiovasculares (em anexo), mas para esta dissertação estudaremos somente os níveis pressóricos.

O exame foi realizado em uma Clínica de Cardiologia, na cidade de Jundiaí. A medida foi realizada com a criança deitada em maca, após um período de repouso e por 
profissional especializado. Para a medida de PA nesse aparelho, a largura do manguito para cada criança avaliada foi adequada às medidas de circunferência e comprimento do braço.

Nesse estudo não será possível classificar as crianças como hipertensas por termos realizado apenas uma medida de PA, ressaltando-se que a hipertensão arterial só é configurada quando os valores de pressão arterial sistólica e/ou diastólica forem maiores ou iguais ao percentil 95 para sexo, idade e percentil de altura, em três ocasiões distintas.

No entanto, a classificação denominada pré-hipertensão foi identificada no trabalho com a finalidade apenas de descrever a população em estudo e ressaltar a importância de medidas preventivas nessa faixa etária.

Para classificar a PA utilizou-se os critérios propostos pelo: The fourth report on the diagnosis, evaluation, and treatment of high blood pressure in children and adolescents (anexo V).

\subsection{Variáveis do estudo}

O enfoque principal do trabalho está na variável explanatória (independente) que corresponde ao peso ao nascer e em variáveis respostas (dependentes) relacionadas à pressão arterial: sistólica $(\mathrm{PAS})$ e diastólica $(\mathrm{PAD})$ e à composição corporal atual: índice de massa corpórea (IMC), área de gordura do braço (AGB) e circunferência da cintura (CC). As variáveis de ajuste para controlar possíveis fatores de confusão foram: escolaridade materna, renda per capita, HDLc, colesterol total, índice de massa corpórea, idade da criança em meses e sexo. 
As demais variáveis são apresentadas somente com o intuito de contextualização do trabalho e descrição desse grupo para futuras aplicações dos resultados obtidos.

\subsection{Análise estatística}

Para o armazenamento e análise estatística dos dados foram utilizados os softwares Epi Info 6.04 e 2000 e Stata versão 9. Para todos os testes estatísticos realizados neste estudo considerou-se valor de $\alpha=0,05$ como nível de significância global.

Para descrição da amostra estudada utilizaram-se freqüências absolutas e relativas, médias, desvios padrão e intervalos de confiança. Foi verificado se as variáveis de interesse para o estudo (antropometria atual, pressão arterial sistólica e diastólica, índice de massa corpórea, área de gordura do braço) apresentavam distribuição normal.

A análise das diferenças de médias das variáveis de interesse foi realizada utilizando-se a Análise de Variância (ANOVA) com teste de Bonferroni ou o teste nãoparamétrico de Kruskal-Wallis. Para a análise de duas amostras independentes foi utilizado o teste $t$ de Student. Para investigar as relações entre PN e as variáveis de interesse foi utilizado o coeficiente de correlação de Pearson.

A análise de regressão multivariada foi realizada a fim de avaliar o impacto das variáveis independentes previamente selecionadas sobre a pressão arterial e 
composição corporal atuais. Todas as variáveis foram tratadas como contínuas no modelo.

Modelagem estatística:

1) Inicialmente foram realizadas análises bivariadas, entre a variável resposta e cada uma das variáveis estudadas, selecionando para entrar no modelo as variáveis com nível descritivo $p \leq 0,20$.

2) As variáveis selecionadas foram incluídas na análise múltipla; nesta etapa, foram selecionadas para continuarem na modelagem as variáveis que apresentaram nível descritivo $\mathrm{p} \leq 0,10$.

Utilizaram-se como variáveis explanatórias principais: peso ao nascer e o comprimento ao nascer. Estas foram analisadas em separado para cada variável resposta, por serem altamente correlacionadas entre si.

As equações usadas na regressão múltipla seguem o modelo geral:

$\mathrm{y}=\mathrm{b} 0+\mathrm{b} 1 \mathrm{xX} 1+\mathrm{b} 2 \mathrm{xX} 2+\ldots . .+\mathrm{bnxXn}$

Onde:

$\mathrm{y}=$ variável resposta (PAS, PAD, IMC, AGB, CC).

b0 = coeficiente quando todas as variáveis são zero. 
bi = estimativa do coeficiente da variável explanatória “i”.

xi = valor da variável explaratória / preditora (peso ao nascer, comprimento ao nascer).

\subsection{Retorno da informação}

Foram entregues os resultados dos exames bioquímicos aos pais ou responsáveis pessoalmente na tentativa de esclarecer qualquer dúvida, pois muitas famílias não teriam oportunidade de levar a criança para uma consulta pediátrica. Nos casos em que fosse detectada qualquer anormalidade, era recomendado que a família buscasse atendimento no serviço de saúde público de mais fácil acesso.

Além disso, realizaram-se palestras incluindo temas como alimentação, crescimento e desenvolvimento das crianças e os principais problemas de saúde que foram identificados durante a aplicação dos questionários.

Na palestra, estavam profissionais como: nutricionista, psicóloga e pediatra. Nessa atividade, foram entregues resultados de exames que ainda não havia sido entregues e nos colocamos a disposição dos familiares para orientá-los quanto a possíveis dúvidas.

\subsection{Questões éticas}

Os procedimentos para o desenvolvimento deste estudo respeitaram o preconizado na resolução 196, de 10 de outubro de 1996, do Conselho Nacional de Saúde (MINISTERIO DA SAÚDE 1997). 
O projeto foi submetido e aprovado pelo Comitê de Ética em Pesquisa da Faculdade de Saúde Pública da Universidade de São Paulo, que regulamentam pesquisas envolvendo seres humanos, sob o protocolo 1122, antes de iniciar a pesquisa (Anexo I).

Também foi esclarecido aos pais e/ou responsáveis pela criança os objetivos e procedimentos a serem realizados. Consentiam a participação no estudo, por meio da assinatura do Termo de Consentimento Livre e Esclarecido e somente os que assinavam o referido documento continuaram participando da coorte. Garantiu-se a liberdade de recusa na participação na pesquisa, sem nenhuma penalidade. Foi garantido a privacidade, confidencialidade e anonimato dos dados das crianças estudadas. 
$\underline{\text { RESULTADOS }}$ 


\subsection{RESULTADOS}

\subsection{Descrição Geral}

Das 745 famílias localizadas, 649 aceitaram participar do estudo e assinaram termo de consentimento, 63 não concordaram em continuar no projeto, 27 mudaram-se para locais distantes do município, e houve óbito de 6 crianças deste o início da coorte entre 1997 e 2000 (Figura 4).

Após a fase de localização para a entrevista domiciliar, foi realizado outro contato por telefone para marcar a aferição das medidas antropométricas e colheita de amostra de sangue para dosagens bioquímicas. Nesta fase, das 649 famílias que responderam o questionário socioeconômico, 509 crianças fizeram as medidas antropométricas e 506 realizaram o exame de sangue. Das 140 crianças que não realizaram exames, 136 foi por desistência dos pais em continuar participando do estudo ou por terem mudado de região e o restante foi por problemas de saúde, como tratamento de câncer (linfoma), Síndrome de Down, HIV positivo e difículdade na realização da punção venosa.

A aferição da pressão arterial foi realizada em dia e local diferente ao dos exames bioquímicos e antropométricos, o que se considerou como a terceira fase do estudo. Compareceram nessa etapa, 472 crianças, sendo este o tamanho da população estudada no trabalho.

Houve, portanto, 27,3\% de perdas levando em consideração o total de mães que foram localizadas e entrevistadas desde a primeira fase (Figura 4). 
FIGURA 4. DISTRIBUIÇÃo NUMÉRICA E PERCENTUAL DAS CRIANÇAS CONVOCADAS PARA O SEGUIMENTO DA COORTE.

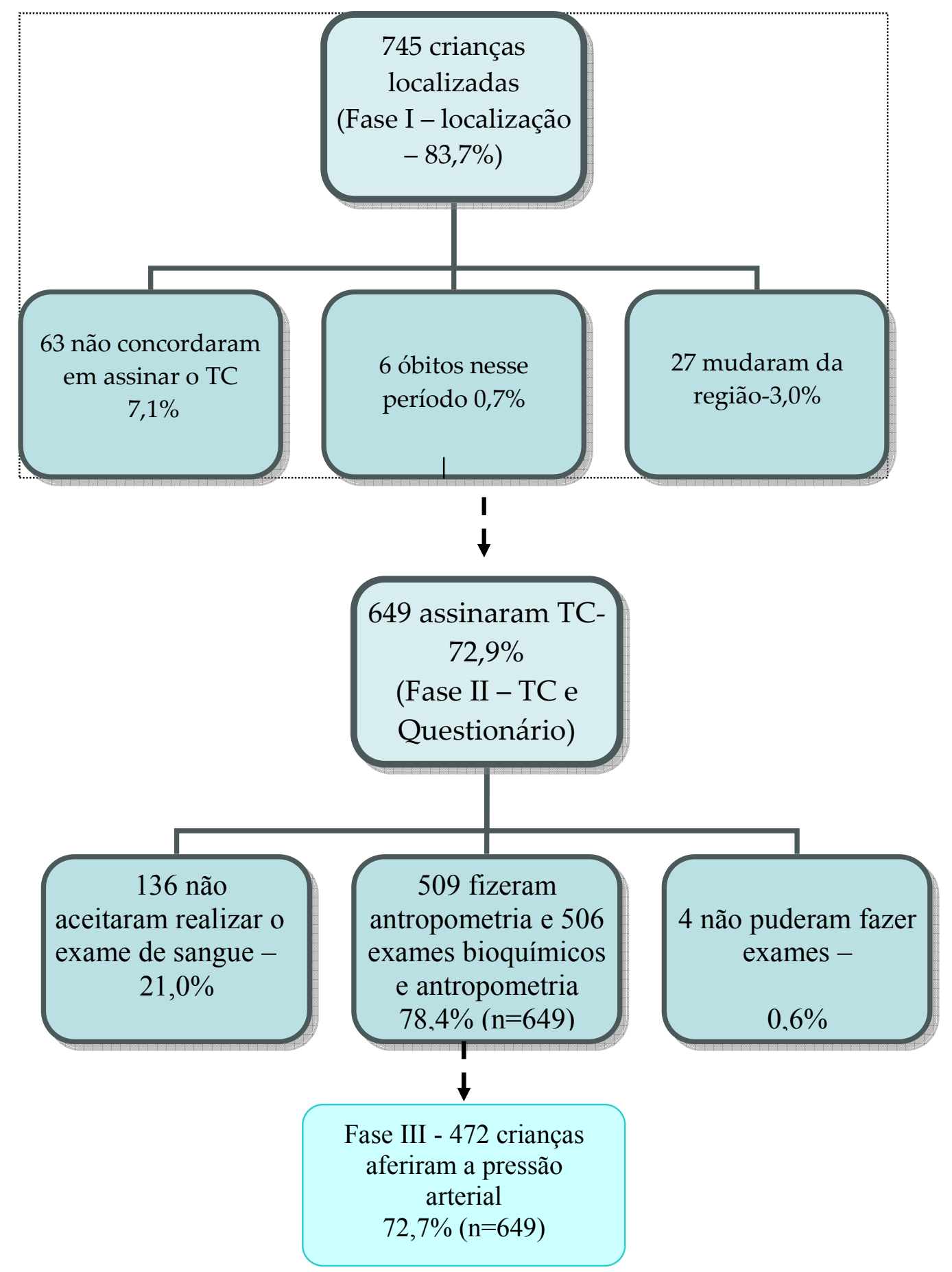


Os motivos mais citados para não participar do estudo foram: falta de tempo das famílias e a não concordância do pai. Além disso, muitas disseram não querer participar por medo ou desconfiança em relação aos exames bioquímicos que seriam realizados nas crianças.

Para reduzir a recusa, os pesquisadores divulgaram anúncios nos principais jornais do município de Jundiaí e convidavam as famílias para irem até o local da coleta para presenciarem como eram realizados os exames e assim poderem esclarecer suas eventuais dúvidas sobre a pesquisa.

TABELA 1 - COMPARAÇÃO DE CARACTERÍSTICAS DAS CRIANÇAS INCLUÍDAS NA COORTE E DAS QUE NÃO CONCLUÍRAM O ESTUDO (PERDAS).

\begin{tabular}{lccc}
\hline \hline Variáveis & $\begin{array}{c}\text { Crianças da coorte } \\
\text { Média }(d p) \\
(n=472 \text { crianças) }\end{array}$ & $\begin{array}{c}\text { Perda } \\
\text { Média }(d p)\end{array}$ & Valor de $p$ \\
\hline \hline $\begin{array}{l}\text { Idade } \\
\text { (meses) }\end{array}$ & $78,88(7,90)$ & $69,85(17,15)$ & 0,010 \\
$\begin{array}{l}\text { Renda per capita } \\
(\mathrm{SM})\end{array}$ & $333,29(284,44)$ & $332,65(251,68)$ & 0,201 \\
$\begin{array}{l}\text { Peso ao Nascer }(\mathrm{g}) \\
\begin{array}{l}\text { Escolaridade Materna } \\
\text { (anos de estudo) }\end{array}\end{array}$ & $3212,19(477,55)$ & $3233,32(478,34)$ & 0,568 \\
\hline \hline
\end{tabular}

A Tabela 1 apresenta a comparação de algumas características observadas nas crianças da coorte e naquelas que não concluíram o estudo (perda). Verificou-se diferença estatisticamente significante somente para a variável idade em meses (teste $t$ de Student, $\mathrm{p}=0,01)$. No entanto, não houve diferença significante para as variáveis: renda per capita, peso ao nascer e níveis de escolaridade materna, nos dois grupos de crianças (teste $t$ de Student, $\mathrm{p}>0,05$ ). 


\subsection{Características socioeconômicas e demográficas}

A Tabela 2 mostra que a coorte ficou composta em sua maioria por crianças do sexo feminino $(53,8 \%)$. Foi observado que 30,93\% das crianças tinham entre 64 e 74 meses de idade, $45,13 \%$ estavam com idade entre 75 a 85 meses e $23,94 \%$ estavam na faixa etária de 86 a 97 meses. A média da idade encontrada para a população foi de $78,77 \pm 7,95$ meses.

Das famílias investigadas, 45,55\% tinham renda familiar de 1 a 3 salários mínimos e apenas 3,39\% recebiam menos de um salário mínimo. A média da renda familiar foi de $1361,37 \pm 1086,83$. Para a renda per capita, observou-se um percentual de $66,95 \%$ de pessoas na família com renda inferior a 1 salário mínimo (salário mínimo $=\mathrm{R} \$ 350,00)$.

Quanto à escolaridade materna, 41,31\% delas estudaram de 5 a 8 anos completos e 19,70\% tinham entre 1 a 4 anos de estudo, com uma média de 8,34 $\pm 8,03$ anos. Atualmente, as mães estão com idade variando entre 19 a 49 anos de idade, sendo que $47,24 \%$ delas situavam-se na faixa etária de 19 a 29 anos e $8,05 \%$ tinham entre 40 a 49 anos de idade.

Os dados sobre as condições de saneamento básico e habitação da coorte mostram que 58,26\% das famílias residem em casa própria, 99,15\% destas eram de tijolos, a água encanada dentro de casa foi referida em 99,78\% dos casos, 98,09\% da energia elétrica era de rede pública e 100,0\% referiram coleta pública de lixo. 
TABELA 2. DISTRIBUIÇÃO DO NÚMERO E PERCENTUAL DE VARIÁVEIS SOCIOECONÔMICAS E DEMOGRÁFICAS DA COORTE.

\begin{tabular}{|c|c|c|c|c|}
\hline Variáveis & $N^{\circ}$ & $\%$ & Média & $d p$ \\
\hline \multicolumn{5}{|l|}{ Sexo } \\
\hline Masculino & 218 & 46,20 & & \\
\hline Feminino & 254 & 53,80 & & \\
\hline \multicolumn{5}{|l|}{ Idade (meses) } \\
\hline $64-74$ & 146 & 30,93 & & \\
\hline $75-85$ & 213 & 45,13 & 78,77 & 7,95 \\
\hline $86-97$ & 113 & 23,94 & & \\
\hline \multicolumn{5}{|l|}{ Renda familiar (SM) } \\
\hline$<1 \mathrm{SM}$ & 16 & 3,39 & & \\
\hline $1-3 \mathrm{SM}$ & 215 & 45,55 & & \\
\hline $3,1-5 \mathrm{SM}$ & 131 & 27,75 & 1361,37 & 1086,83 \\
\hline$>5 \mathrm{SM}$ & 110 & 23,31 & & \\
\hline \multicolumn{5}{|l|}{ Renda per capita (SM) } \\
\hline$<1 \mathrm{SM}$ & 316 & 66,95 & & \\
\hline $1-3 \mathrm{SM}$ & 146 & 30,72 & & \\
\hline $3,1-5 \mathrm{SM}$ & 7 & 1,48 & 331,04 & 277,53 \\
\hline$>5 \mathrm{SM}$ & 4 & 0,85 & & \\
\hline \multicolumn{5}{|l|}{ Escolaridade da Mãe } \\
\hline $1-4$ anos & 93 & 19,70 & & \\
\hline $5-8$ anos & 195 & 41,31 & & \\
\hline $9-16$ anos & 176 & 37,29 & 8,34 & 8,03 \\
\hline Sem informação & 8 & 1,70 & & \\
\hline
\end{tabular}


5.3. Medidas antropométricas e idade gestacional ao nascer

Na Tabela 3, verificou-se o percentual de crianças que nasceram com restrição do crescimento intra-uterino - RCIU $(13,57 \%)$, também denominado por alguns de pequenas para idade gestacional $(\mathrm{PIG})$, pré-termos $(2,62 \%)$ e grandes para idade gestacional - GIG (4,81\%). Os valores mínimo e máximo do PN foram 1355g e 4710g, respectivamente, e a média e desvio padrão foi de $3208,16 \pm 483,27$ g. Além disso, $26,27 \%$ das crianças da coorte nasceram com peso deficiente ou insuficiente (25002999g).

TABELA 3. DISTRIBUIÇÃo DO NÚMERO E PERCENTUAL DE VARIÁVEIS ESTUDADAS.

\begin{tabular}{lcccc}
\hline \multicolumn{1}{c}{ Variáveis } & $N^{\circ}$ & $\%$ & Média & $d p$ \\
\hline \hline Idade Gestacional $(n=457)$ & 12 & 2,62 & & \\
$<37$ & 442 & 96,72 & 39,16 & 1,32 \\
$37-42$ & 3 & 0,66 & & \\
$>42$ & & & \\
Crescimento intra-uterino* & 62 & 13,57 & \\
RCIU( $\leq$ percentil 10) & 22 & 4,81 & \\
GIG ( $\geq$ percentil 90 ) & & & \\
Peso ao nascer(g) & 27 & 5,72 & \\
$<2500$ & 124 & 26,27 & & \\
$2500-2999$ & 195 & 41,31 & & \\
$3000-3499$ & 103 & 21,82 & 3208,16 & 483,27 \\
$3500-3999$ & 23 & 4,87 & & \\
4000 ou mais & & & & \\
Comprimento ao nascer $(\mathrm{cm}, n=457)$ & 170 & 37,2 & 48,11 & \\
37 - 47 & 287 & 62,8 & & \\
48 - 55 & & & \\
\hline \hline
\end{tabular}




\subsection{Estado Nutricional}

\subsubsection{Antropometria e Composição Corporal}

A Tabela 4 mostra o estado nutricional das crianças, classificadas segundo a curva do CDC 2000, usando IMC para idade. O percentual de crianças com risco de sobrepeso e sobrepeso é de $22,66 \%$ e com baixo peso é de $9,54 \%$. Quando se separa por sexo, observa-se um maior percentual de meninas com risco de sobrepeso, aproximadamente $17,00 \%$.

TABELA 4. CLASSIFICAÇÃO DAS CRIANÇAS, SEGUNDO IMC PARA IDADE (CDC 2000).

\begin{tabular}{|c|c|c|c|c|c|c|}
\hline \multirow{2}{*}{$\begin{array}{c}\text { Estado Nutricional } \\
\text { IMC** }^{*}\end{array}$} & \multicolumn{2}{|c|}{ Geral } & \multicolumn{2}{|c|}{ Meninos } & \multicolumn{2}{|c|}{ Meninas } \\
\hline & $N$ & $\%$ & $N$ & $\%$ & $N$ & $\%$ \\
\hline Baixo Peso & 45 & 9,54 & 20 & 9,17 & 25 & 9,84 \\
\hline Normal & 320 & 67,80 & 156 & 71,56 & 164 & 64,57 \\
\hline Risco de Sobrepeso & 67 & 14,19 & 24 & 11,01 & 43 & 16,93 \\
\hline Sobrepeso & 40 & 8,47 & 18 & 8,26 & 22 & 8,66 \\
\hline Total & 472 & 100,00 & 218 & 100,00 & 254 & 100,00 \\
\hline
\end{tabular}


Foram calculados, média e desvio padrão e os respectivos intervalos de confiança a 95\% para todas as variáveis antropométricas (Tabela 5). Verificou-se que as medidas antropométricas foram similares para meninos e meninas, somente diferindo na circunferência do braço $(\mathrm{p}=0,002)$.

TABELA 5. VALORES MÉDIOS, DESVIO PADRÃO E INTERVALOS DE CONFIANÇA A 95\% DAS VARIÁVEIS ANTROPOMÉTRICAS.

\begin{tabular}{|c|c|c|c|}
\hline Variáveis & Média (DP) & IC -95\% & Valor de p \\
\hline \multicolumn{4}{|c|}{ Peso atual (kg) } \\
\hline Meninos & $23,81(5,37)$ & $23,10-24,53$ & 0,260 \\
\hline Meninas & $24,23(5,16)$ & $23,59-24,86$ & \\
\hline Geral & $24,04(5,26)$ & $23,56-24,51$ & \\
\hline \multicolumn{4}{|l|}{ Altura (m) } \\
\hline Meninos & $122,18(6,63)$ & $121,29-123,06$ & 0,629 \\
\hline Meninas & $122,42(7,45)$ & $121,50-123,34$ & \\
\hline Geral & $122,31(7,08)$ & $121,67-122,95$ & \\
\hline \multicolumn{4}{|l|}{$\mathrm{IMC}\left(\mathrm{kg} / \mathrm{m}^{2}\right)$} \\
\hline Meninos & $15,83(2,40)$ & $15,51-16,15$ & 0,123 \\
\hline Meninas & $16,03(2,27)$ & $15,75-16,31$ & \\
\hline Geral & $15,94(2,33)$ & $15,73-16,15$ & \\
\hline \multicolumn{4}{|l|}{$\mathrm{CB}(\mathrm{cm})$} \\
\hline Meninos & $18,45(2,45)$ & $18,12-18,78$ & 0,002 \\
\hline Meninas & $18,94(2,52)$ & $18,62-19,25$ & \\
\hline Geral & $18,71(2,50)$ & $18,48-18,94$ & \\
\hline \multicolumn{4}{|l|}{$\mathrm{CC}(\mathrm{cm})$} \\
\hline Meninos & $56,06(6,34)$ & $55,21-56,91$ & 0,100 \\
\hline Meninas & $57,00(6,81)$ & $56,16-57,84$ & \\
\hline
\end{tabular}


Geral $\quad 56,57(6,61) \quad 55,97-57,16$

IMC=índice de massa corporal; $\mathrm{CB}=$ circunferência do braço; $\mathrm{CC}=$ circunferência da cintura.

A Tabela 6 expõe os valores médios, desvio padrão e intervalos de confiança a 95\% das variáveis de composição corporal, além de apresentar o valor de p de cada variável em relação ao sexo, pelo teste de Kruskal-Wallis. Houve diferenças estatisticamente significantes $(\mathrm{p}<0,001)$ entre os valores de PCT, PCS e AGB e a variável sexo.

TABELA 6. VALORES MÉDIOS, DESVIOS PADRÃO E INTERVALOS DE CONFIANÇA A 95\% DAS VARIÁVEIS DE COMPOSIÇÃO CORPORAL.

\begin{tabular}{cccc}
\hline \hline Variáveis & Média $(\mathbf{d p})$ & IC -95\% & Valor de $\mathbf{p}$ \\
\hline \hline PCT (mm) & & & \\
Meninos & $9,40(3,13)$ & $8,98-9,82$ & $<0,001$ \\
Meninas & $10,78(3,22)$ & $10,38-11,18$ & \\
Geral & $10,14(3,25)$ & $9,85-10,43$ & \\
PCS (mm) & & & \\
Meninos & $6,39(3,00)$ & $5,99-6,79$ & $<0,001$ \\
Meninas & $7,45(3,26)$ & $7,04-7,85$ & \\
Geral & $6,96(3,18)$ & $6,67-7,25$ & \\
AGB (cm) & & & \\
Meninos & $8,21(3,87)$ & $7,70-8,73$ & $<0,001$ \\
Meninas & $9,54(3,86)$ & $9,06-10,02$ & \\
Geral & $8,93(3,92)$ & $8,57-9,28$ & \\
AMB (cm) & & & \\
Meninos & $19,35(4,64)$ & $18,73-19,97$ & 0,413 \\
Meninas & $19,57(4,46)$ & $19,02-20,12$ & \\
&
\end{tabular}


$\overline{\mathrm{PCT}}=$ prega cutânea tricipital; $\mathrm{PCS}=$ prega cutânea subscapular; $\mathrm{AGB}=$ área de gordura do braço; $\mathrm{AMB}=$ área muscular do braço.

\subsection{Perfil lipídico da coorte}

Foi realizada uma análise descritiva dos elementos bioquímicos, calculando suas médias e desvios padrão, os valores mínimos e máximos para cada variável e o intervalo de $95 \%$ de confiança entre as médias.

O colesterol total (CT) apresentou média de 158,54 \pm 29,69; valores mínimo e máximo de $82,00 \mathrm{mg} / \mathrm{dl}$ e $381,00 \mathrm{mg} / \mathrm{dl}$, respectivamente. A média do HDLc foi de $55,32 \pm 11,19 \mathrm{mg} / \mathrm{dl}$; valores mínimo e máximo de 29,00 mg/dl e 130,00 mg/dl,

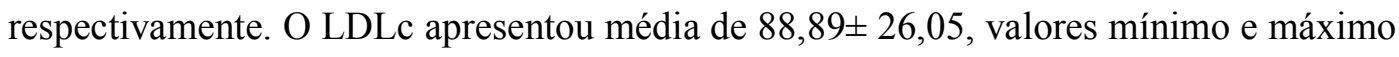
de $29,00 \mathrm{mg} / \mathrm{dl}$ e $310 \mathrm{mg} / \mathrm{dl}$, respectivamente. A média do TG foi de $71,71 \pm 32,13$ mg/dl, valor mínimo e máximo de 20,00 mg/dl e 306,00 mg/dl, respectivamente (Tabela 7). 
TABEla 7. VALORES MÉdios, deSVios PADRÃo (dp) MíNiMo E MÁXiMo E INTERVALOS DE CONFIANÇA DAS VARIÁVEIS BIOQUÍMICAS.

\begin{tabular}{|c|c|c|c|c|}
\hline Variáveis & Média (dp) & Mínimo & Máximo & IC $-95 \%$ \\
\hline CT (mg/dl) & $158,54(29,69)$ & 82 & 381 & $155,86-161,23$ \\
\hline HDL-c (mg/dl) & $55,32(11,19)$ & 29 & 130 & $54,31-56,33$ \\
\hline LDL-c (mg/dl) & $88,89(26.05)$ & 29 & 310 & $86,53-91,24$ \\
\hline TG (mg/dl) & $71,71(32,13)$ & 20 & 306 & $68,80-74,61$ \\
\hline
\end{tabular}

5.6. Avaliação da Pressão Arterial

A Tabela 8 mostra que a prevalência de crianças com pressão arterial sistólica $\geq 95$ foi muito alta $(35,16 \%)$. A prevalência de pressão arterial diastólica $\geq 95$ foi de $5,09 \%$. As meninas apresentaram maior prevalência de $\mathrm{PA} \geq 95$, tanto para pressão arterial sistólica $(42,52 \%)$, como para diastólica $(8,27 \%)$. Os valores médios e desvios padrão da pressão arterial sistólica e da diastólica das crianças da coorte foi de 111,43 \pm 12,83 e $58,36 \pm 9,32$, respectivamente. Houve diferença significativa entre as variáveis PAS ( $p=0,001), \operatorname{PAD}(p=0,005)$ e sexo. 
TABela 8. Distribuição do NÚMERo E DESVIO PADRÃo (dp) DA PAS e PAD EM PERCENTIL, SEGUNDO SEXO.

\begin{tabular}{|c|c|c|c|c|c|c|c|c|}
\hline \multirow[t]{3}{*}{ Sexo } & \multicolumn{4}{|c|}{$\mathrm{PAS}^{1}$} & \multicolumn{4}{|c|}{$\begin{array}{l}\mathrm{PAD}^{2} \\
\end{array}$} \\
\hline & \multicolumn{2}{|c|}{$<95$} & \multicolumn{2}{|c|}{$\geq 95$} & \multicolumn{2}{|c|}{$<95$} & \multicolumn{2}{|c|}{$\geq 95$} \\
\hline & $\bar{N}$ & $\%$ & $\bar{N}$ & $\%$ & $\mathrm{~N}$ & $\%$ & $\bar{N}$ & $\%$ \\
\hline Menino $(n=218)$ & 160 & 73,40 & 58 & 26,60 & 215 & 98,62 & 3 & 1,38 \\
\hline Menina $(n=254)$ & 146 & 57.48 & 108 & 42,52 & 233 & 91,73 & 21 & 8,27 \\
\hline Geral (n=472) & 306 & 64,83 & 166 & 35,16 & 448 & 94,91 & 24 & 5,09 \\
\hline Média (dp) & \multirow{2}{*}{\multicolumn{4}{|c|}{$\begin{array}{c}111,43(12,83) \\
0.001\end{array}$}} & \multicolumn{4}{|c|}{$58,36(9,32)$} \\
\hline Valor de $p^{*}$ & & & & & & & & \\
\hline
\end{tabular}

(*) Teste Exato de Fisher; (1)=pressão arterial sistólica; (2)=pressão arterial diastólica

5.7. Relação do peso e do comprimento ao nascer sobre a pressão arterial e a composição corporal atuais.

Foram realizadas correlações (Pearson) entre as variáveis respostas relacionadas à antropometria, composição corporal, pressão arterial e as variáveis explanatórias: peso ao nascer e comprimento ao nascer, distribuídas na Tabela 9.

As variáveis que melhor representam a adiposidade (CC, AGB e IMC) mostraram uma forte correlação positiva entre si. O peso ao nascer mostrou uma correlação positiva com as seguintes variáveis antropométricas: Peso $(\mathrm{r}=0,26)$, Altura $(\mathrm{r}=0,22)$ e IMC $(\mathrm{r}=0,21)$ e composição corporal: $\mathrm{CC}(\mathrm{r}=0,20), \mathrm{AGB}(\mathrm{r}=0,16)$, que são variáveis relacionadas com a adiposidade central. 
Em relação à pressão arterial, encontrou-se correlação (Pearson) mais forte da pressão arterial sistólica com as variáveis antropométricas e de composição corporal do que em relação a pressão arterial diastólica.

Não houve correlação significante entre peso ao nascer e pressão arterial sistólica e diastólica. Resultado semelhante verificou-se para a variável: comprimento ao nascer em relação as pressões atuais(Tabela 9).

TABELA 9. COEFICIENTE DE CORRELAÇÃO DE PEARSON (r) E VALORES DE (p) ENTRE PESO AO NASCER E AS VARIÁVEIS ESTUDADAS.

\begin{tabular}{llllllllll}
\hline \hline & & & & & & & & & \\
Variáveis & PAS & PAD & Peso & Altura & CC & IMC & AGB & PN & CN \\
\hline \hline PAS & 1 & & & & & & & & \\
PAD & $0.73^{*}$ & 1 & & & & & & & \\
Peso & $0.29^{*}$ & $0.18^{*}$ & 1 & & & & & & \\
Altura & $0.20^{*}$ & $0.17^{*}$ & $0,73^{*}$ & 1 & & & & & \\
CC & $0.30^{*}$ & $0.19^{*}$ & $0.90^{*}$ & $0.52^{*}$ & 1 & & & & \\
IMC & $0.27^{*}$ & 0.14 & $0.85^{*}$ & $0.28^{*}$ & $0.88^{*}$ & 1 & & & \\
AGB & $0.26^{*}$ & $0.15^{*}$ & $0.81^{*}$ & $0.41^{*}$ & $0.86^{*}$ & $0.84^{*}$ & 1 & & \\
PN & $-\mathbf{0 . 0 6}$ & $\mathbf{- 0 . 0 6}$ & $\mathbf{0 . 2 6 ^ { * }}$ & $\mathbf{0 . 2 2 ^ { * }}$ & $\mathbf{0 . 2 0 ^ { * }}$ & $\mathbf{0 . 2 1 *}$ & $\mathbf{0 . 1 6 *}$ & $\mathbf{1}$ & \\
CN & $\mathbf{- 0 . 0 7}$ & $\mathbf{- 0 . 0 5}$ & $\mathbf{0 . 1 7 ^ { * }}$ & $\mathbf{0 . 1 9 ^ { * }}$ & $\mathbf{0 . 1 1 ^ { * * }}$ & $\mathbf{0 . 0 9}$ & $\mathbf{0 , 0 7}$ & $\mathbf{0 , 7 6}$ & $\mathbf{1}$ \\
\hline \hline
\end{tabular}

Coeficiente de Pearson (* $\mathrm{p}<0,001)$; Coeficiente de Pearson (** $\mathrm{p}=0,01)$; PAS (pressão arterial sistólica); PAD (pressão arterial diastólica); CC (circunferência da cintura); IMC (indice de massa corpórea); AGB (área de gordura do braço); PN (peso ao nascer); $\mathrm{CN}$ (comprimento ao nascer).

As figuras 5 e 6 ilustram os resultados apresentados na Tabela 10 e 11, mostrando a análise de regressão simples da pressão arterial sistólica (Figura 5; Tabela 10) e da pressão arterial diastólica (Figura 6; Tabela 11) em relação ao peso ao nascer. Verifica-se que não houve relação inversa significante, mas que é possível observar o coeficiente negativo $(\beta=-0,0016$ para PAS e $\beta=-0,0012$ para PAD). 
FIGURA 5. REGRESSÃO LINEAR DA PRESSÃO ARTERIAL SISTÓLICA - PAS, SEGUNDO PESO AO NASCER.

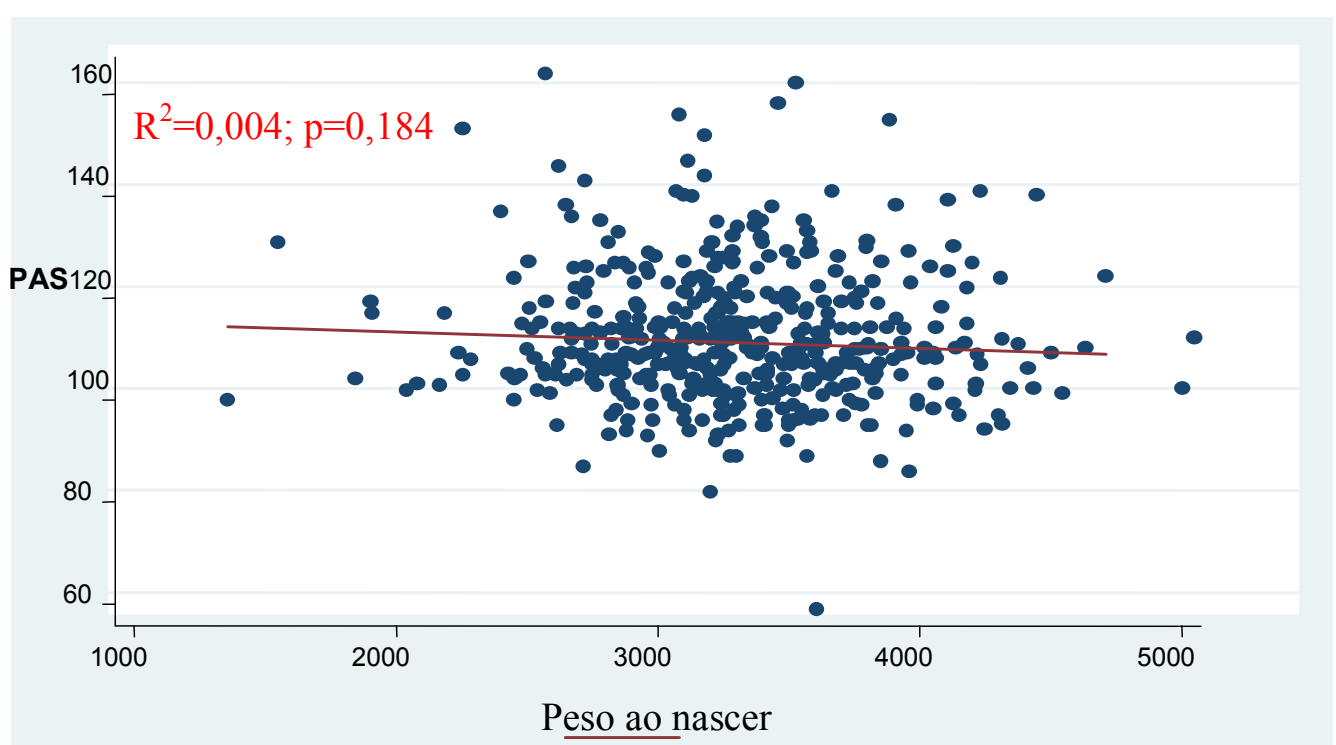

FIGURA 6. REGRESSÃo LINEAR dA PRESSÃo ARTERIAL DIASTÓliCA - PAD, SEGUNDO PESO AO NASCER.

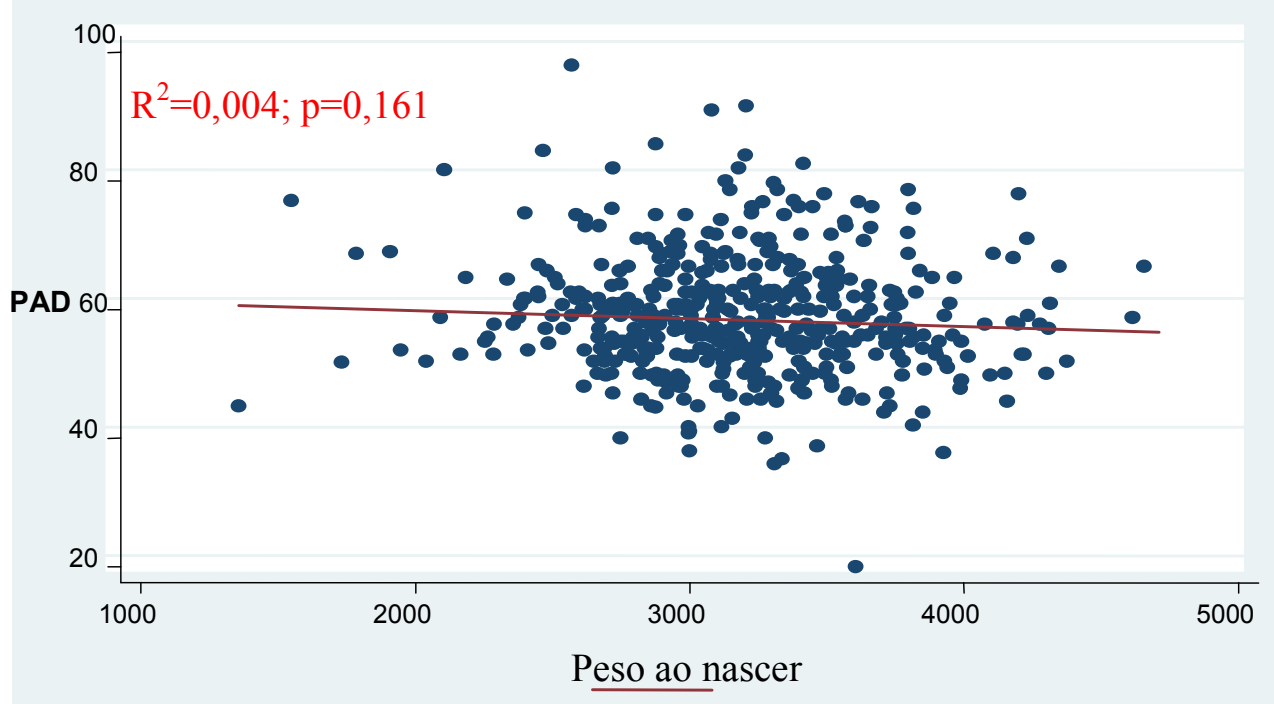


TABELA 10. REGRESSÃO LINEAR DA PRESSÃO ARTERIAL SISTÓLICA (PAS). COEFICIENTES, ERROS PADRÃO, INTERVALOS DE CONFIANÇA E NÍVEIS DESCRITIVOS DO TESTE.

\begin{tabular}{|c|c|c|c|c|c|}
\hline Variável & Coeficiente & Erro Padrão & \multicolumn{2}{|c|}{$\mathrm{IC}(95 \%)$} & $\mathrm{p}$ \\
\hline \multicolumn{6}{|c|}{ Regressão simples } \\
\hline Peso ao Nascer & $-0,0016$ & 0,001 & 0,0040 & 0,0008 & 0,184 \\
\hline Constante & 116,65 & 3,967 & 108,85 & 124,44 & 0,000 \\
\hline \multicolumn{6}{|c|}{ Regressão múltipla * } \\
\hline Peso ao Nascer & $-0,0029$ & 0,0012 & $-0,0053$ & $-0,0005$ & 0,016 \\
\hline Sexo & 1,6324 & 1,1525 & $-0,6324$ & 3,8973 & 0,157 \\
\hline Índice de Massa Corpórea & 1.6017 & 0,2483 & 1,1138 & 2,0897 & 0,000 \\
\hline Constante & 0,148 & 0,007 & 0,134 & 0,161 & 0,000 \\
\hline Variável & Coeficiente & Erro Padrão & IC ( & $5 \%)$ & $\mathrm{p}$ \\
\hline \multicolumn{6}{|c|}{ Regressão simples } \\
\hline Comprimento ao Nascer & $-0,4248$ & 0,2702 & $-0,9558$ & 0,1062 & 0,117 \\
\hline Constante & 131,911 & 13,015 & 106,335 & 157,488 & 0,000 \\
\hline \multicolumn{6}{|c|}{ Regressão múltipla * } \\
\hline Comprimento ao Nascer & $-0,5152$ & 0,2631 & $-1,0323$ & 0,0018 & 0,051 \\
\hline Sexo & 1,7459 & 1,1703 & $-0,5540$ & 4,0458 & 0,136 \\
\hline Índice de Massa Corpórea & 1,5732 & 0,2469 & 1,0879 & 2,0585 & 0,000 \\
\hline Constante & 108,50 & 13,261 & 82,84 & 134,56 & 0,000 \\
\hline
\end{tabular}

$\left({ }^{*}\right)$ As variáveis: idade em meses $(\mathrm{p}=0,22)$, HDLc $(\mathrm{p}=0,98)$, colesterol total $(\mathrm{p}=0,21)$, renda per capita $(\mathrm{p}=0,49)$, escolaridade da mãe $(\mathrm{p}=0,35)$ foram sequencialmente excluídas do modelo por não apresentarem associação com a variável dependente.

A Tabela 10 apresenta, além da análise de regressão simples, a análise de regressão múltipla explorando a variável resposta pressão arterial sistólica, notandose significância no modelo final para as variáveis: índice de massa corpórea e peso 
ao nascer. Houve uma associação no limite de significância entre PAS e comprimento ao nascer $(\mathrm{p}=0.051)$.

Realizou-se o estudo da interação entre sexo x peso ao nascer e índice de massa corpórea x peso ao nascer, porém não se encontrou nenhuma interação entre estas variáveis, mostrando que sexo e índice de massa corpórea são fatores de confusão, mas não modificam o efeito do peso ao nascer sobre a pressão arterial sistólica.

TABELA 11. REGRESSÃO LINEAR DA PRESSÃo ARTERIAL DIASTÓlICA (PAD). COEFICIENTES, ERROS PADRÃO, INTERVALOS DE CONFIANÇA E NÍVEIS DESCRITIVOS DO TESTE.

\begin{tabular}{|c|c|c|c|c|c|}
\hline Variável & Coeficiente & Erro Padrão & \multicolumn{2}{|c|}{ IC $(95 \%)$} & $\mathrm{p}$ \\
\hline \multicolumn{6}{|c|}{ Regressão simples } \\
\hline Peso ao Nascer & $-0,0012$ & 0,0009 & 0,0030 & 0,0004 & 0,161 \\
\hline Constante & 62,35 & 2,87 & 56,70 & 68,01 & 0,000 \\
\hline \multicolumn{6}{|c|}{ Regressão múltipla * } \\
\hline Peso ao Nascer & $-0,0014$ & 0,0009 & $-0,0032$ & 0,0003 & 0,126 \\
\hline Sexo & 2,5725 & 0,8574 & 0,8877 & 4,2573 & 0,003 \\
\hline Índice de Massa Corpórea & 0,5827 & 0,1847 & 0,2197 & 0,9457 & 0,002 \\
\hline Constante & 0,148 & 0,007 & 0,134 & 0,161 & 0,000 \\
\hline Variável & Coeficiente & Erro Padrão & IC ( & $5 \%)$ & $\mathrm{p}$ \\
\hline \multicolumn{6}{|c|}{ Regressão simples } \\
\hline Comprimento ao Nascer & $-0,2084$ & 0,1959 & $-0,5935$ & 0,1767 & 0,288 \\
\hline Constante & 68,39 & 9,44 & 49,85 & 86,94 & 0,000 \\
\hline \multicolumn{6}{|c|}{ Regressão múltipla * } \\
\hline
\end{tabular}




\begin{tabular}{lccccc}
\hline Comprimento ao Nascer & $-0,1655$ & 0,1954 & $-0,5494$ & 0,2184 & 0,397 \\
Sexo & 2,7758 & 0,8690 & 1,0681 & 4,4835 & 0,001 \\
Índice de Massa Corpórea & 0,5705 & 0,1833 & 0,2102 & 0,9309 & 0,002 \\
Constante & 52,96 & 9,85 & 33,61 & 72,31 & 0,000 \\
\hline \hline
\end{tabular}

$\left(^{*}\right)$ As variáveis: idade em meses $(\mathrm{p}=0,24)$, colesterol HDL $(\mathrm{p}=0,67)$, colesterol total $(\mathrm{p}=0,45)$, renda per capita $(\mathrm{p}=0,54)$, escolaridade da mãe $(\mathrm{p}=0,21)$ foram sequencialmente excluídas do modelo por não apresentarem associação com a variável dependente.

$\mathrm{Na}$ Tabela 11, os dados da análise de regressão simples mostram que nenhuma diferença foi encontrada para peso ao nascer e pressão arterial diastólica (PAD), e o mesmo foi observado para a variável explanatória: comprimento ao nascer, nesse modelo.

Na regressão múltipla, somente as variáveis sexo e índice de massa corpórea apresentaram efeitos significantes na PAD e o peso ao nascer e comprimento ao nascer parecem não influenciar a PAD atual.

Realizou-se o estudo da interação entre sexo e o peso ao nascer e também do índice de massa corpórea com o peso ao nascer, porém não se encontrou nenhuma interação entre estas variáveis, mostrando que sexo e índice de massa corpórea são fatores de confusão, mas não modificam o efeito do peso ao nascer sobre a pressão arterial diastólica. O mesmo foi feito com a variável explanatória: comprimento ao nascer e encontraram-se resultados semelhantes. 
TABELA 12. REGRESSÃo LINEAR DA ÁREA DE GORDURA DO BRAÇO (AGB). COEFICIENTES, ERROS PADRÃO, INTERVALOS DE CONFIANÇA E NÍVEIS DESCRITIVOS DO TESTE.

\begin{tabular}{|c|c|c|c|c|c|}
\hline Variável & Coeficiente & Erro Padrão & \multicolumn{2}{|c|}{$\mathrm{IC}(95 \%)$} & $\mathrm{p}$ \\
\hline \multicolumn{6}{|c|}{ Regressão simples } \\
\hline Peso ao Nascer & 0,0013 & 0,0003 & 0,0006 & 0,0020 & 0,001 \\
\hline Constante & 4,80 & 1,20 & 2,45 & 7,16 & 0,000 \\
\hline \multicolumn{6}{|c|}{ Regressão múltipla } \\
\hline Peso ao Nascer & 0,0001 & 0,0002 & $-0,0003$ & 0,0005 & 0,710 \\
\hline Sexo & 1,0513 & 0,1965 & 0,6652 & 1,4374 & 0,000 \\
\hline Índice de Massa Corpórea & 1,3909 & 0,0423 & 1,3077 & 1,4741 & 0,000 \\
\hline Constante & $-15,11$ & 0,92 & $-16,91$ & $-13,30$ & 0,000 \\
\hline Variável & Coeficiente & Erro Padrão & $\mathrm{IC}($ & $5 \%)$ & $\mathrm{p}$ \\
\hline \multicolumn{6}{|c|}{ Regressão simples } \\
\hline Comprimento ao Nascer & 0,1252 & 0,0828 & $-0,0374$ & 0,2879 & 0,131 \\
\hline Constante & 2,90 & 3,99 & $-4,93$ & 10,73 & 0,467 \\
\hline \multicolumn{6}{|c|}{ Regressão múltipla } \\
\hline Comprimento ao Nascer & 0,0290 & 0,0452 & $-0,0599$ & 0,1180 & 0,521 \\
\hline Sexo & 1,0795 & 0,2013 & 0,6839 & 1,4750 & 0,000 \\
\hline Índice de Massa Corpórea & 1,3890 & 0,0425 & 1,3055 & 1,4724 & 0,000 \\
\hline Constante & $-16,27$ & 2,28 & $-20,75$ & $-11,78$ & 0,000 \\
\hline
\end{tabular}

$\left({ }^{*}\right)$ As variáveis: idade em meses $(\mathrm{p}=0,18)$, HDLc $(\mathrm{p}=0,77)$, colesterol total $(\mathrm{p}=0,16)$, renda per capita $(\mathrm{p}=0,57)$, escolaridade da mãe $(\mathrm{p}=0,40)$ foram sequencialmente excluídas do modelo por não apresentarem associação com a variável dependente.

Os resultados da análise de regressão simples para a área de gordura do braço (Tabela 12), mostram diferença significativa entre o peso ao nascer e a AGB. O comprimento ao nascer não mostrou associação significante com a AGB na análise simples. 
No ajuste do modelo as variáveis sexo e indice de massa corpórea estão mais fortewmente associadas com a AGB. Porém, nota-se que as variáveis explanatórias principais: peso ao nascer e comprimento ao nascer perdem seu efeito no modelo ajustado.

TABELA 13. REGRESSÃO LINEAR DA CIRCUNFERÊNCIA DA CINTURA (CC). COEFICIENTES, ERROS PADRÃO, INTERVALOS DE CONFIANÇA E NÍVEIS DESCRITIVOS DO TESTE.

\begin{tabular}{|c|c|c|c|c|c|}
\hline Variável & Coeficiente & Erro Padrão & \multicolumn{2}{|c|}{ IC $(95 \%)$} & $\mathrm{p}$ \\
\hline \multicolumn{6}{|c|}{ Regressão simples } \\
\hline Peso ao Nascer & 0,0027 & 0,0006 & 0,0015 & 0,0039 & 0,000 \\
\hline Constante & 47,88 & 2,00 & 43,94 & 51,83 & 0,000 \\
\hline \multicolumn{6}{|c|}{ Regressão múltipla } \\
\hline Peso ao Nascer & 0,0003 & 0,0003 & $-0,0003$ & 0,0008 & 0,359 \\
\hline Idade (meses) & 0,1003 & 0,0176 & 0,0656 & 0,1350 & 0,000 \\
\hline Índice de Massa Corpórea & 2,4573 & 0,0614 & 2,3366 & 2,5779 & 0,000 \\
\hline Constante & 8,63 & 1,82 & 5,06 & 12,19 & 0,000 \\
\hline Variável & Coeficiente & Erro Padrão & $\mathrm{IC}\left(C_{9}\right.$ & $5 \%)$ & $\mathrm{p}$ \\
\hline \multicolumn{6}{|c|}{ Regressão simples } \\
\hline Comprimento ao Nascer & 0,3317 & 0,1389 & 0,0587 & 0,6047 & 0,017 \\
\hline Constante & 2,90 & 3,99 & $-4,93$ & 10,73 & 0,467 \\
\hline \multicolumn{6}{|c|}{ Regressão múltipla } \\
\hline Comprimento ao Nascer & 0,1165 & 0,0641 & $-0,0095$ & 0,2426 & 0,070 \\
\hline Idade (meses) & 0,0997 & 0,0178 & 0,0648 & 0,1347 & 0,000 \\
\hline Índice de Massa Corpórea & 2,4613 & 0,0609 & 2,3415 & 2,5811 & 0,000 \\
\hline Constante & 3,86 & 3,50 & $-3,02$ & 10,75 & 0,270 \\
\hline
\end{tabular}

$\left({ }^{*}\right)$ As varíáveis: $\operatorname{sexo}(\mathrm{p}=0,18)$, HDLc $(\mathrm{p}=0,42)$, colesterol total $(\mathrm{p}=0,32)$, renda per capita $(\mathrm{p}=0,73)$, escolaridade da mãe $(\mathrm{p}=0,40)$ foram sequencialmente excluídas do modelo por não apresentarem associação com a variável dependente. 
$\mathrm{Na}$ tabela 13, nota-se que na regressão simples, as variáveis: peso ao nascer e comprimento ao nascer exercem efeito significante sobre a circunferência da cintura (CC).

No entanto, as variáveis que permaneceram no modelo final, idade e índice de massa corpórea, mostraram forte relação com circunferência da cintura, inclusive fazendo com que as variáveis explanatórias: $\mathrm{PN}$ e $\mathrm{CN}$ percam o efeito significante sobre a variável resposta estudada: circunferência da cintura. As variáveis: idade e índice de massa corpórea não apresentaram interação com peso ou comprimento ao nascer, mas podem ser consideradas como fator de confusão.

TABELA 14. REGRESSÃO LINEAR DO ÍNDICE DE MASSA CORPÓREA (IMC). COEFICIENTES, ERROS PADRÃO, INTERVALOS DE CONFIANÇA E NÍVEIS DESCRITIVOS DO TESTE.

\begin{tabular}{|c|c|c|c|c|c|}
\hline Variável & Coeficiente & $\begin{array}{c}\text { Erro } \\
\text { Padrão }\end{array}$ & \multicolumn{2}{|c|}{$\mathrm{IC}(95 \%)$} & $\mathrm{p}$ \\
\hline \multicolumn{6}{|c|}{ Regressão simples } \\
\hline Peso ao Nascer & 0,0010 & 0,0002 & 0,0006 & 0,0014 & 0,000 \\
\hline Constante & 12,74 & 0,71 & 11,35 & 14,13 & 0,000 \\
\hline \multicolumn{6}{|c|}{ Regressão múltipla * } \\
\hline Peso ao Nascer & 0,0010 & 0,0002 & 0,0006 & 0,0014 & 0,000 \\
\hline Idade (meses) & 0,0202 & 0,0132 & $-0,0057$ & 0,0462 & 0,127 \\
\hline Constante & 11,13 & 1,26 & 8,64 & 13,62 & 0,000 \\
\hline Variável & Coeficiente & $\begin{array}{c}\text { Erro } \\
\text { Padrão }\end{array}$ & IC $(c$ & $5 \%)$ & $\mathrm{p}$ \\
\hline \multicolumn{6}{|c|}{ Regressão simples } \\
\hline Comprimento ao Nascer & 0,0967 & 0,0492 & 0,0001 & 0,1933 & 0,050 \\
\hline Constante & 2,90 & 3,99 & $-4,93$ & 10,73 & 0,467 \\
\hline \multicolumn{6}{|c|}{ Regressão múltipla } \\
\hline
\end{tabular}




\begin{tabular}{lccccc}
\hline Comprimento ao Nascer & 0,1020 & 0,0492 & 0,0054 & 0,1987 & 0,038 \\
ldade (meses) & 0,0233 & 0,0137 & $-0,0035$ & 0,0502 & 0,088 \\
Constante & 9,19 & 2,66 & 3,96 & 14,42 & 0,001 \\
\hline
\end{tabular}

(*) As variáveis: sexo $(\mathrm{p}=0,34)$, HDLc $(\mathrm{p}=0,37)$, colesterol total $(\mathrm{p}=0,23)$, renda per capita $(\mathrm{p}=0,24)$, escolaridade da mãe $(\mathrm{p}=0,74)$ foram sequencialmente excluídas do modelo por não apresentarem associação com a variável dependente.

FIGURA 7. REGRESSÃO LINEAR DO ÍNDICE DE MASSA CORPÓREA - IMC, SEGUNDO PESO AO NASCER.

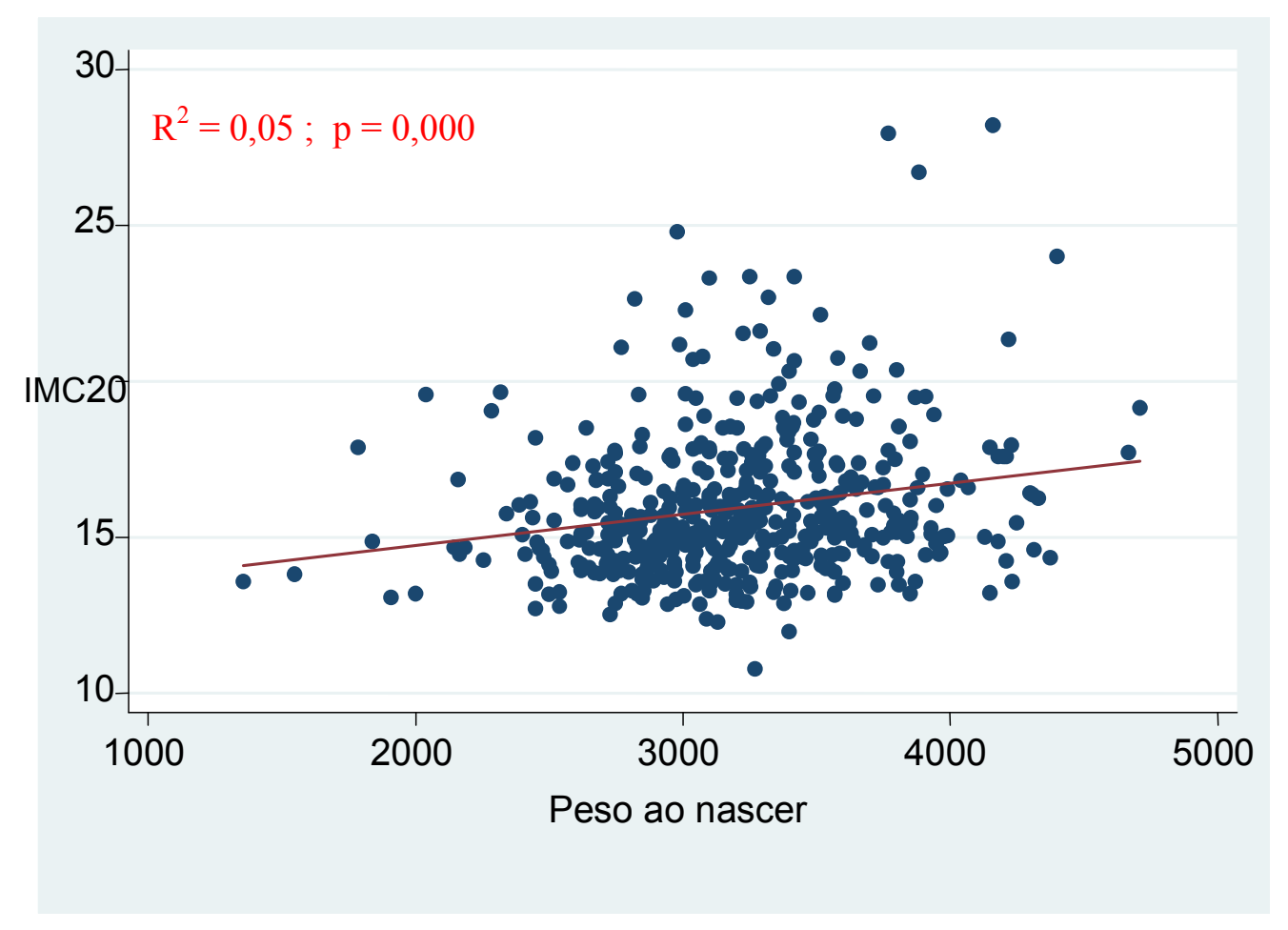

A figura 7 ilustra os resultados apresentados na Tabela 14, mostrando a análise de regressão simples do índice de massa corpórea em relação ao peso ao nascer. Verifica-se que houve relação significante, sendo possível observar o coeficiente positivo no valor de $\beta=0,0016$. 
Os resultados da análise de regressão para índice de massa corpórea (Tabela 14), tanto no modelo simples quanto no modelo ajustado, mostram diferença significativa entre o indice de massa corpórea e as variáveis peso e comprimento ao nascer. Neste caso, a única variável que continuou no modelo final foi a idade em meses da criança, porém não se evidenciou, diferenças significativas entre idade e índice de massa corpórea. 
DISCUSSÃO 


\subsection{DISCUSSÃO}

\subsection{Comentários Gerais}

No Brasil, há uma preocupação básica com a atenção à saúde/doença na infância e na adolescência. Sua boa prática tem impacto significativo na redução da morbimortalidade em toda a faixa etária pediátrica, com declínio da desnutrição e de várias doenças infecciosas. Assim, em razão do aumento da expectativa de vida nas últimas décadas, o grande desafio agora passa a ser a prevenção de doenças crônicas do adulto e do idoso, que na sua maior parte tem raízes na infância ou mesmo na vida intrauterina.

Nos últimos anos, um conjunto crescente de evidências tem sustentado a idéia de que distúrbios ocorridos em períodos críticos do desenvolvimento fetal podem determinar alterações permanentes ou de longo prazo na fisiologia ou morfologia de um determinado órgão (ASHTON 2000). Importantes linhas de pesquisa surgiram na busca de uma melhor compreensão das doenças cardiovasculares, a partir da demonstração da associação do baixo peso ao nascer e o desenvolvimento de hipertensão arterial na idade adulta (BOMFIM 2005).

Este estudo foi realizado com o propósito de verificar a influência do peso ao nascer sobre a pressão arterial e a composição corporal de crianças na idade de 5 a 8 anos. Tendo em vista a necessidade de estudos que contribuam para a prevenção e a detecção precoce de fatores de risco em crianças, de modo a proporcionar intervenções que permitam uma melhor qualidade de vida para o adulto, no futuro. 
Os estudos de coorte são ideais para avaliar a relação entre exposição e doença, pois permitem o acompanhamento dos participantes ao longo do tempo. Entretanto, essa vantagem pode constituir ponto crítico devido às perdas no decorrer do seguimento, que podem comprometer os resultados obtidos.

Uma das formas de avaliar o comprometimento dessa possível limitação é realizar a comparação de algumas variáveis que caracterizam a população estudada com a dos indivíduos que não prosseguiram no estudo e são designados como perdas. No presente estudo, não se observou diferença estatística entre os dois grupos, exceto para a variável idade da criança, a qual no grupo de perda as crianças apresentaram-se com menor idade. Sugere-se que a necessidade de colheita de sangue principalmente nas crianças menores foi um fator que contribuiu para as perdas na coorte. No entanto, esta variável não interfere ou diferencia os dois grupos, evidenciando-se que as crianças que permaneceram no estudo constituíram amostra representativa da população originalmente selecionada, sem prejuízo para os resultados apresentados.

Portanto, a análise comparativa de algumas variáveis de interesse verificadas nas crianças da coorte e no grupo de crianças desistentes, permite-nos inferir que apesar de um percentual elevado de perda (27,3\%), a validade interna do estudo foi resguardada, uma vez que não foram encontradas diferenças significativas entre as duas populações (crianças participantes $v s$ desistentes). 


\subsection{Características socioeconômicas e demográficas da coorte}

Ao analisar a complexa rede de causalidade do estado de nutrição infantil, evidenciam-se os fatores básicos que o condicionaram e sua relação com as variáveis socioeconômicas das famílias. Fatores socioeconômicos, sociais e biológicos têm sido constantemente relacionados com índices de déficit nutricional em variados contextos (UNICEF 2001).

As condições de renda e de escolaridade observadas neste estudo caracterizaram a população como de baixo poder aquisitivo, uma vez que a maioria dos pais estudaram 5 a 8 anos completos, o que corresponde ao ensino fundamental e que $45,55 \%$ das crianças eram mantidas com renda familiar mensal de 1 a 3 salários mínimos. A renda média per capita dessas famílias era menor que 1 salário mínimo (SM - R\$ 331,03), com $66,95 \%$ deles recebendo menos de 1 salário por pessoa. Vale ressaltar que, estes resultados refletem o perfil de renda familiar mensal apresentados na Pesquisa Nacional por amostras de Domicílios (PNAD) realizada no país nos anos de 2002 e 2003 pelo IBGE (2004) onde 29,2\% da população do estado de São Paulo apresentou de 1 a 2 salários mínimos como renda familiar mensal.

No entanto, a renda é uma informação difícil de ser obtida, sobretudo em populações de baixas condições de vida, onde predomina a informalidade das atividades econômicas. O caráter aleatório da ocupação e da renda por diferentes pessoas de uma mesma família, faz desse indicador uma variável insegura, com o agravante do viés que pode ser induzido por interesses próprios dos entrevistados, substimando ou superestimando os valores reais dos orçamentos domésticos. 
Os dados sobre as condições de moradia e saneamento básico da coorte mostraram que a população estudada apresentava condições de moradias satisfatórias, no que se refere à construção dos domicílios, ao abastecimento de água e energia elétrica e ao sistema de coleta de lixo. Ressaltando o perfil de condição de moradia da população brasileira, obtido pela última Pesquisa de Orçamentos Familiares realizada no país, para os anos de 2002 e 2003 (IBGE 2004). Segundo essa pesquisa, no Brasil urbano, os serviços de água, coleta de lixo, iluminação pública, energia elétrica e drenagem foram considerados bons para a maioria das famílias entrevistadas.

\subsection{Medidas antropométricas e idade gestacional ao nascer}

A prevalência de baixo peso ao nascer (5,7\%) neste estudo, mostra uma concordância com outros resultados obtidos, que encontraram uma importante redução da prevalência de baixo peso ao nascer no Brasil. Em 1989, de cada 100 crianças que nasciam 10 pesavam menos de 2,5 kg (10\%). Em 1996, esse índice foi reduzido para 9,2\%, embora seja relevante lembrar que todos os anos, no Brasil, 270 mil bebês ainda nascem com baixo peso (IBGE 2004).

Vale ressaltar que estes dados de peso ao nascer foram coletados entre os anos de 1997 e 2000, na cidade de Jundiaí, estado de São Paulo. E que no primeiro estudo (RONDÓ 2003) não foram incluídas mulheres com gestação de risco, o que pode ter colaborado com a baixa prevalência de baixo peso ao nascer no estudo original.

Ao avaliar o peso ao nascer médio da coorte $(3208,16 \mathrm{~g})$, verifica-se que os valores são superiores ao encontrado por MONTEIRO et al (2000), para o município de 
São Paulo $(3160,0 \mathrm{~g})$. É também relevante a prevalência de $26,27 \%$ de crianças que nasceram com peso deficiente ou insuficiente $(2500-2999 \mathrm{~g})$, nesta coorte, o que constitui fator de preocupação para o potencial crescimento e desenvolvimento das crianças, além do aumento no risco de morbimortalidade e de atraso do desenvolvimento neuropsicomotor (DEWEY 1998).

Houve uma associação estatisticamente significante $(p=0,042)$ entre PN e sexo. Concordando com o estudo de ALBERMAN \& EVANS 1992, que mostrou uma distribuição masculina do PN deslocando-se consistentemente no sentido dos pesos maiores, em comparação ao sexo feminino.

A prevalência de crianças que nasceram com RCIU ou PIG - pequenas para idade gestacional foi de $13,57 \%$ e grandes para a idade gestacional - GIG foi de 4,81\%. A classificação foi realizada segundo a relação do peso ao nascer com idade gestacional, considerando-se os pontos de corte $\leq$ ao percentil 10 e $\geq$ ao percentil 90 para classificálas como PIG e GIG, respectivamente (WILLIANS et al 1982). A proporção de prétermo encontrada nesta coorte foi de 2,62\% em 457 nascimentos, valor inferior ao encontrado no estudo de COSTA \& GOUTLIEB (1998), realizado em municípios do estado de São Paulo, que variou de $4,8 \%$ e $9,0 \%$.

Muitas das causas de RCIU ou de nascimento PIG são preveníveis. No nosso meio, a desnutrição materna, o tabagismo, o uso de drogas e as doenças infecciosas são as causas principais de comprometimento do crescimento fetal e podem ser evitadas. As consequências biológicas de ter nascido pequeno podem ser observadas já na infância, com a não recuperação do crescimento e, na vida adulta, com o aparecimento de doenças cardiovasculares e metabólicas (HALES et al 1992). 


\subsection{Estado Nutricional}

\subsubsection{Antropometria e Composição Corporal}

$\mathrm{Na}$ área das ciências da saúde, principalmente da Nutrição, um dos procedimentos básicos de diagnóstico é a antropometria; considerando-se que a carência ou excesso de alguns nutrientes é a principal causa das doenças crônico-degenerativas, tais como obesidade, hipertensão, cardiopatias, diabetes, câncer, problemas circulatórios e renais; as quais, representam um verdadeiro flagelo à humanidade, tanto no passado quanto no presente.

No presente estudo, utilizando-se o percentil do IMC da população de referência (CDC 2000) para classificação do estado nutricional, obteve-se uma freqüência alta de baixo peso $(9,54 \%)$, concomitante a altas proporções de "risco de sobrepeso" $(14,19 \%)$ e sobrepeso $(8,47 \%)$. A soma destes dois percentuais revela uma freqüência de crianças com excesso de peso corporal de 22,66\%.

Ao contrário do que ocorre para a população adulta, não há consenso sobre os critérios antropométricos mais adequados para classificar o estado nutricional de crianças. Existem vários pontos de corte e critérios de classificação para diferentes populações, tornando difícil a comparação das prevalências de desnutrição, de risco de sobrepeso (denominado em muitos estudos de sobrepeso) e sobrepeso (denominado também de obesidade) aqui encontrados. Não foi localizado, qualquer artigo brasileiro utilizando o percentil de IMC em relação à população de referência CDC 2000 para uma população com idade de 5 a 8 anos, semelhante ao nosso estudo. 
No entanto, comparando-se os resultados aqui apresentados com os do ENDEF (Estudo Nacional de Despesa Familiar) e do PNSN (Plano Nacional de Saúde e Nutrição), percebe-se que no Brasil, no decorrer das duas últimas décadas, existe além dos já antigos e habituais quadros de desnutrição, o surgimento de sobrepeso e obesidade, inclusive; entre as faixas etárias de nossos pré-escolares, escolares e adolescentes (MONTEIRO 2000, SICHIERI 1992).

Ao verificar nesse estudo, a presença de baixo peso em menor proporção que o excesso de peso, confirma a existência da transição nutricional, caracterizada nos últimos anos pela redução da desnutrição e aumento da obesidade em diferentes países.

No presente estudo, houve uma grande semelhança das medidas antropométricas entre os sexos, com uma diferença estatisticamente significante nas medidas de circunferência do braço. Ao comparar os valores médios aqui apresentados com os valores de referência (CDC 2000) verificou-se uma semelhança entre as medidas. No entanto, ressalta-se que este é um padrão de referência americano, mas que é considerado uma amostra representativa, selecionada de forma adequada, tendo sido recomendado pela Organização Mundial da Saúde.

Diversos estudos publicados na última década confirmam a importância da distribuição da gordura corporal como melhor preditor para o risco cardiovascular do que a obesidade generalizada (LI et al 2006).

Os indicadores antropométricos mais utilizados para o diagnóstico da obesidade centralizada são a relação entre as medidas das circunferências cintura e do quadril (RCQ) e a medida da circunferência da cintura (CC). A CC é melhor indicadora da massa adiposa visceral, estando fortemente relacionada com as doenças cardiovasculares. Neste trabalho, apresentamos os valores de CC para esta população 
com média de $56,57 \mathrm{~cm}$, não havendo diferença estatisticamente significante entre os sexos. Não existem pontos de corte e distribuição de referência para esta medida antropométrica, para que possa ser comparada com nossos achados.

MAST et al (1998), avaliando a composição corporal por medidas antropométricas, observou que diferenças entre os sexos, na massa de gordura e na distribuição de gordura corporal foram óbvias em crianças com idade de 5 a 7 anos. Em nosso estudo, perceberam-se valores maiores de medidas de composição corporal, relacionadas à adiposidade (PCT, PCS e AGB) para meninas, com diferenças estatisticamente significante $(\mathrm{p}<0,001)$.

\subsection{Perfil Lipídico da Coorte}

O presente estudo determinou a distribuição dos lipídeos séricos em amostra representativa de crianças, assim como a associação destas com o peso ao nascer. Os níveis de lipídeos e lipoproteínas séricos sofrem profundas mudanças durante o crescimento e o desenvolvimento, havendo duas fases de aumento expressivo de seus níveis: até o $2^{\circ}$ ano de vida e durante a maturação sexual (BERTRAIS 2000).

Para população pediátrica, os valores de referência para o perfil lipídico de acordo com a I Diretriz de prevenção da aterosclerose na infância e na adolescência são: colesterol total $<150 \mathrm{mg} / \mathrm{dL} ;$ LDL-C $<100 \mathrm{mg} / \mathrm{dL} ;$ HDL-C $\geq 45 \mathrm{mg} / \mathrm{dL}$ e triglicérides $<$ $100 \mathrm{mg} / \mathrm{dL}$ (SOCIEDADE BRASILEIRA DE CARDIOLOGIA 2005).

As crianças avaliadas apresentaram uma média de colesterol total (CT) superior aos valores de referência propostos para a faixa etária de 2 a 19 anos (SOCIEDADE BRASILEIRA DE CARDIOLOGIA 2005). Quando algum dos componentes do perfil lipídico apresentam concentrações acima dos valores de referência, caracteriza-se como 
um quadro de dislipidemia. No entanto, os valores de HDL colesterol, triglicérides e LDL colesterol tiveram valores inferiores aos de referência.

Neste trabalho verificamos a relação estatisticamente significante entre sexo apenas para HDL - colesterol, com valores mais baixos no sexo feminino. Importantes estudos epidemiológicos nacionais e internacionais sobre distribuição de lipídeos nas crianças mostram níveis elevados de todas as lipoproteínas e lipídeos no gênero feminino, independente da idade ou cor da pele (MORRISON 1999).

De acordo com a classificação da I Diretriz de prevenção da aterosclerose na infância e adolescência (2005), observou-se que a prevalência de crianças com elevadas concentrações de HDL-c foi substancialmente superior a outros estudos com amostras regionalizadas (GERBER e ZIELINSKY 1997, GIULIANO et al 2005, GUEDES et al 2006, RIBEIRO et al 2006). No estudo de GUEDES et al (2006) utilizaram-se 35 mg/dL como valor de referência e nos estudos de GERBER e ZIELINSKI (1997) e RIBEIRO et al (2006) utilizaram-se $40 \mathrm{mg} / \mathrm{dl}$ como valores de referência de HDL-c, diferentes do utilizado em nosso estudo.

Exames em adultos jovens demonstram que lesões ateroscleróticas estão comumente presentes em artérias coronárias em indivíduos com menos de vinte anos, o que sugere que a gênese da aterosclerose muitas vezes se inicia na infância e adolescência. Neste sentido, estudos epidemiológicos conduzidos com crianças e adolescentes têm evidenciado como principais fatores de risco para doenças cardiovasculares a hipertensão arterial e as concentrações elevadas de colesterol e lipoproteínas no sangue (BROTONS et al 1998). 


\subsection{Avaliação da Pressão Arterial}

A mensuração da pressão arterial em crianças é mais variável do que em adultos. Portanto, uma criança classificada em uma ocasião como hipertensa ou portadora de hipertensão limítrofe pode apresentar valores dentro da faixa normal após vários dias ou semanas (NHBPEP 2004). A regra, portanto, é extrema cautela na interpretação de mensurações ocasionais de pressão sanguínea em indivíduos jovens.

A prevalência de crianças com pressão arterial sistólica $\geq 95$ foi muito alta $(35,16 \%)$. A prevalência de pressão arterial diastólica $\geq 95$ foi de $5,09 \%$. Foi possível observar maior prevalência de meninas com PA $\geq 95$, tanto para pressão arterial sistólica (42,52\%), como para diastólica $(8,27 \%)$, mas não houve diferença significante entre os sexos.

No entanto, é importante lembrar que níveis pressóricos elevados devem ser confirmados em visitas repetidas antes de caracterizar o sujeito como hipertensos. A variabilidade nas mensurações de pressão sanguínea em crianças está relacionada aos mecanismos biológicos que a regulam. Alguns dos mecanismos de regulação agem apenas a curto prazo e de maneira praticamente aguda, enquanto outros estão envolvidos na manutenção e controle da pressão sanguínea a longo prazo (SCHREUDER \& NAUTA 2007, BARKER 2006).

A confirmação dos elevados níveis pressóricos é necessária, pois altos níveis de pressão arterial tendem a diminuir em subseqüentes mensurações, como resultado de efeito de redução da ansiedade do paciente, por exemplo. Portanto, para uma caracterização mais precisa do nível de pressão arterial o ideal é realizar uma média de mensurações múltiplas tiradas através de semanas e meses (NHBPEP 2004). 


\subsection{Relação do peso e comprimento ao nascer com a pressão arterial e composição corporal}

Encontrou-se associação negativa significante entre peso ao nascer e pressão arterial sistólica em crianças de 5 a 8 anos de idade. Os valores indicam que estatisticamente essas variáveis têm relação inversa entre si, mas que a variável peso ao nascer, isoladamente, não prediz elevação da PAS.

O peso ao nascer é apenas uma medida bruta do crescimento fetal e da nutrição intra-uterina; outros índices como perímetro cefálico, peso placentário, relação peso placentário/peso ao nascer refletem com maior precisão o tempo, a gravidade e a resposta do feto ao agravo intra-uterino (ADABAG 2001) e devem também ser explorados em estudos subseqüentes. Os dados antropométricos do recém-nascido foram coletados no estudo principal de RONDÓ (2003) e poderão ser utilizados em análise posterior.

Os nossos achados mostram que o PN tem associação com a PAS na idade atual das crianças, mas que essa relação é dependente de outros fatores como o sexo e o índice de massa corpórea. Os resultados de estudos que investigam a relação da pressão arterial elevada com o peso ao nascer são controversos e existem poucos dados na literatura internacional que avaliem crianças na faixa etária semelhante a essa população.

ROSTAND et al (2005) avaliaram crianças de 5 anos de idade e verificaram uma associação inversa significante entre peso ao nascer e pressão arterial elevada em crianças de cor branca, mas não encontraram para crianças negras, sugerindo que a etnia 
possa influenciar os resultados. No entanto, PEARCE \& O'SULLIVAN (2003) não encontraram relação estatisticamente significante entre peso ao nascer e variação da pressão arterial sistólica ou diastólica em 976 crianças e adolescentes de 7 a 16 anos de idade, mesmo após ajustes de possíveis variáveis de confusão.

As explicações para esses resultados discordantes da clássica hipótese proposta por Barker poderiam ser associadas a outros fatores que influenciam diretamente os níveis pressóricos das crianças. O comprometimento do peso nos primeiros anos de vida, a ausência de aleitamento materno, a idade, a velocidade de recuperação ponderoestatural de recém-nascidos com baixo peso, também poderiam contribuir para elevar os níveis de pressão arterial (SINGHAL et al 2001), mais do que o peso ao nascer de forma isolada.

Alguns estudos mostram maiores riscos de morte por doença coronariana em homens que apresentaram menor peso com um ano de idade, sugerindo que o período crítico, de maior influência da nutrição nas doenças cardiovasculares se estende da fase intra-uterina até o primeiro ano de vida pós-natal (BARKER et al 1989).

Ao avaliar o impacto do comprimento ao nascer sobre a pressão arterial, observamos que este apresenta menor efeito tanto para pressão arterial sistólica como diastólica. Observa-se que na regressão múltipla o índice de massa corpórea aumenta esse efeito para a pressão sistólica, pela associação do peso ao nascer com o índice de massa corpórea atuais. Ao verificar a interação entre peso ao nascer e índice de massa corpórea, não se observa significância, constatando que o IMC também é um fator de risco independente para elevação da PAS.

O estudo de LAW et al 2000 mostrou que o aumento da pressão arterial em crianças de três populações distintas da China, América do Sul e América Central estão 
relacionados à redução do tamanho corporal ao nascer. Eles verificaram que para a população do Chile, ao ajustar a pressão arterial segundo peso atual, houve um aumento de um milímetro de mercúrio $(1 \mathrm{mmHg})$ na $\mathrm{PA}$ para cada centímetro $(\mathrm{cm})$ de redução no comprimento ao nascer. Os resultados do estudo de Jundiaí não sustentam essa idéia, verificando-se que o comprimento ao nascer não se relacionou com a PA. Outros estudos relatam que medidas adequadas de comprimento ao nascer seria fator protetor em relação ao desenvolvimento de hipertensão arterial e doenças cardiovasculares (GASKIN et al 2000, LEON et al 2000).

No que se refere à análise do peso ao nascer com a composição corporal, este estudo mostrou que a área de gordura do braço, circunferência da cintura e IMC apresentam uma relação positiva com peso ao nascer. Na regressão múltipla ocorre uma perda dessa significância ao incluir no modelo, principalmente o índice de massa corpórea, que isoladamente apresenta uma maior associação com o aumento da pressão arterial sistólica ou diastólica.

A obesidade é uma das principais causas de elevação da pressão arterial em crianças e adolescentes, favorecendo complicações cérebro-vasculares e cardiovasculares futuras. SOROF et al 2004, mostraram que a hipertensão arterial aumenta progressivamente com o índice de massa corpórea, com prevalências de $2 \%$ no percentil 5 de índice de massa corpórea e de 11\% no percentil 95 de índice de massa corpórea.

A importância da distribuição de gordura como fator de risco para doenças cardiovasculares em adultos é bem documentada. Um padrão de excesso de gordura na região abdominal, integrando a síndrome metabólica, é associado com risco elevado 
para doença cardiovascular, como a hipertensão, quando comparado com padrão de depósito periférico de gordura (DANIELS et al 1999).

Encontrou-se uma correlação positiva entre as medidas de circunferência da cintura e área de gordura do braço e as pressões arteriais sistólica ou diastólica, enquanto que o IMC correlacionou-se apenas com pressão arterial sistólica, sugerindo a importância do depósito periférico de gordura e do excesso de gordura abdominal na associação de maior risco de doença cardiovascular, incluindo a elevação da pressão arterial.

Ressalta-se que as crianças estudadas apresentavam uma faixa etária muito homogênea, com média de idade de aproximadamente 6 anos, e que estudos mostram que essa relação inversa de pressão arterial e PN é melhor identificada a partir da adolescência. GIULIANO et al (2005) afirmam que a partir de 1 ano de idade, a pressão arterial sistólica se eleva progressivamente até a adolescência. Porém, a pressão arterial diastólica se eleva após os 5 ou 6 anos de idade, proporcional à sistólica e, semelhante ao que encontramos, os coeficientes de correlação da pressão arterial sistólica, idade e índices antropométricos são maiores que os observados para a pressão arterial diastólica.

De acordo com os dados apresentados, torna-se evidente que o peso e comprimento ao nascer apresentam associação significante com o IMC, PAS e sexo. No entanto não se pode predizer, com estes resultados, que uma criança com pesos mais baixos ao nascimento terá consequentemente alterações metabólicas ou fatores de risco cardiovasculares como elevação da pressão arterial na infância, adolescência ou idade adulta. 
Identificou-se que o peso ao nascer, precisa ser ainda mais explorado como fator de risco para o desenvolvimento de doenças cardiovasculares, principalmente, ao estudar sua relação com a PA. Essa relação de PA x PN é difícil de ser investigada, pois muitas variáveis socioeconômicas, ambientais e biológicas podem interferir nos resultados devendo-se controlar pelos potenciais fatores de confusão, como fizemos em nossas análises.

Estudos como este motiva a investigação e o diagnóstico precoce da restrição de crescimento na fase fetal e sua prevenção por meio de medidas de simples execução como o acompanhamento do exame pré-natal e do crescimento e desenvolvimento na infância. A vigilância mais rigorosa de profissionais de saúde na promoção do estado nutricional adequado, especialmente nos primeiros anos de vida precisam ser incentivados na prática de saúde pública. 
CONCLUSÃO 


\subsection{CONCLUSÕES}

Os resultados do presente estudo mostram que:

- O peso ao nascer tem uma associação inversa com pressão arterial sistólica, mas não mostra influência na pressão arterial diastólica.

- O peso ao nascer associou-se positivamente com índice de massa corpórea, circunferência da cintura e área de gordura do braço.

- Apesar da associação positiva entre peso ao nascer e índice de massa corpórea, verificou-se que não há interação entre estas duas variáveis, mostrando que são fatores de risco independentes para a elevação da pressão arterial.

- É evidente que o peso ao nascer apresenta associação significante com a PAS, IMC, AGB, CC e sexo. No entanto, não podemos predizer pelos resultados encontrados, que uma criança com pesos mais baixos ao nascimento, terá maiores valores de PA e/ou alterações metabólicas na infância, adolescência ou idade adulta.

- Ao avaliar o impacto do comprimento ao nascer sobre a pressão arterial, observou-se que este possui menor influência tanto para a pressão arterial sistólica como para a diastólica.

- O comprimento ao nascer apresenta associação positiva com índice de massa corpórea e circunferência da cintura. 


\subsection{CONSIDERAÇÕES FINAIS}

Nas últimas décadas, houve grandes mudanças no perfil nutricional das populações, caracterizada pelo aumento das doenças crônicas não transmissíveis (DCNT) e redução das doenças infecciosas entre adultos e crianças, assim como pela ocorrência simultânea de ambas nas regiões em desenvolvimento.

Estudos têm sugerido uma associação entre hipertensão arterial, obesidade e dislipidemias na infância e na vida adulta e maior risco para desenvolver as DCNT. Diversos fatores têm sido associados a esse fenômeno, entre esses, o peso ao nascer, tornando-o um dos mais importantes temas de Saúde Pública da atualidade (BARKER DJP 2007).

Contudo, o tema proposto para estudo ainda é controverso, sendo que algumas publicações apresentam pontos discordantes e outros que evidenciam uma associação negativa do peso ao nascer com os valores de pressão arterial, principalmente a sistólica, semelhante ao evidenciado nesse trabalho.

Mas, apesar da associação negativa encontrada, não foi possível estimar, o quanto o peso ao nascer contribui para o surgimento de alterações na composição corporal e na pressão arterial, especialmente na idade estudada, de 5 a 8 anos. No entanto, ressalta-se a importância de mais estudos serem realizados nesta área, pois são inúmeras as lacunas no conhecimento deste campo de investigação.

Acreditamos enfaticamente na importância do estudo da "origem fetal das doenças", conceito introduzido por BARKER et al (1993) e de sua grande relevância para os países em desenvolvimento, porque oferece mais elementos para o manejo e controle dos efeitos da transição epidemiológica e nutricional que eles atravessam. 
$\underline{\text { REFERÊNCIAS }}$ 


\subsection{REFERÊNCIAS}

Adabag AS. Birth weight and the future risk of cardiovascular disease: Does intrauterine malnutrition have a role in fetal programming? J Lab Clin Med 2001; 138: $378-86$.

Alberman E \& Evans SJW. A epidemiologia da prematuridade: etiologia, freqüência e prognóstico. Ann Nestlé.1992, 44:5-24.

Ashton N. Perinatal development and adult blood pressure. Braz J Med Biol Res. $2000 ; 33: 731-40$.

Barker DJP, Winter PD, Osmmond C, Margetts B, Simonds SJ. Weight in infancy and death from ischaemic heart disease. Lancet. 1989; 334: 577-580.

Barker DJ, Bull AR, Osmond C \& Simmonds SJ. Fetal and placental size and risk of hypertension in adult life. BMJ. 1990; 301:259-262.

Barker DJP, Hales CN, Fall Child, Osmond C, Philips K, Clark PMS. Type2 (noninsulin-dependent) diabetes mellitus, hypertension and hyperlipidaemia (Syndrome X): Relation to reduced fetal growth. Diabetol. 1993; 36: 62-67.

Barker DJP. Mothers, Babies and Disease in Later Life. $1^{0}$ Ed. 1994.

Barker DJ, Martyn CN, Osmond C, Wield GA. Abnormal liver growth in utero and death from coronary heart disease. BMJ 1995; 310(6981):703-4. 
Barker DJP. Mothers, Babies and Health in Later Life. $2^{\circ}$ Ed. Edinburgh:

Churchild Livingstone. 1998.

Barker DJP. Adult consequences of fetal growth restriction. Clin Obstet Gynecol 2006; 49: 270-283.

Barker DJP. Obesity and early life. Obesity Reviews. 2007; 8 (suppl 1): 45-49.

Benediktsson R, Lindsay RS, Noble J, Seckl JR, Edwards CR. Glucocorticoid exposure in utero: new model for adult hypertension. Lancet. 1993;341:339-41.

Bertrais S, Balkau B, Charles MA, et al. Puberty-associated differences in total cholesterol and triglyceride levels according to sex in French children aged 10-13 years. Ann Epidemiol 2000; 10: 316-23.

Bernabé JV, Soriano T, Albaladejo R, Juarranz M, Calle ME, Martinez D, Domínguez-Rojas V. Risk factors for low birth weight: a review. European J Obstetr \& Gynecol and Repr Biol. 2004; 116(1): 3-15.

Bomfim AS; Mandarim-de-Lacerda CA. Programação pré-natal de hipertensão arterial na vida adulta. Rev da SOCERJ, 2005; 18(6): 510-515.

Brotons C, Ribera A, Perich RM, et al. Worldwide distribution of blood lipids and lipoproteins in childhood and adolescence: a review study. Atherosclerosis.1998; 139:1-9. 
Cameron N. The measurement of human growth. $1^{\text {a }}$ ed. London: Croom Helm; 1984.

Capurro H, Konichezki S, Fonseca D, Caldeiro-Barcia. A simplified method for diagnosis of gestational age in the newborn infant. J Pediatr. 1978; 93:120-2.

Centers for Disease Control and Prevention and National Center for Health Statistics.2000 CDC grow charts: United States [online] Hyaltsville; 2002a [cited 2002 May 11] available from: http://www.cdc.gov/growthcharts

Centers for Disease Control and Prevention and National Center For Health Statistics. Growth chart revision update [online] Hyaltsville; 2002a [cited 2002 May 11] http://www.cdc.gov/nchs/about/major/nhanes/gcrevision.htm.

Costa CE \& Goutlieb, SLD. Estudo epidemiológico do peso ao nascer a partir da Declaração de Nascido Vivo: an epidemiological approach. Rev.Saúde Pública 1998; 32 (4): 328-334.

Daniels SR. Is there an epidemic of cardiovascular disease on the horizon? $\mathbf{J}$ Pediatr. 1999;134:665-6.

Daniels SR, Khoury PR \& Morrison JA. Utility of different measures of body fat distribution in children and adolescents. Am J Epidemiol. 2000; 152:1179-84.

Daniels SR. Cardiovascular sequelae of childhood hypertension. Am J Hypertens. 2002;15(2 Pt 2):S61-3. 
Dean AG, Dean JA, Culombier D. Epi-Info version 6: a word processing database and statistics program for epidemiology on microcomputers. Atlanta: Centers of Disease and Control and Preventions; 1994.

Dewey KG. Cross-cultural patterns of growth and nutritional status of breast-fed infants. Am J Clin Nutr. 1998; 67: 10-7.

de Onis M, Blossner M, Villar J. Levels and patterns of intrauterine growth retardation in developing countries. Eur J Clin Nutr 1998; 52. Suppl 1:5-15.

Edwards LJ, Coulter CL, Symonds ME, McMillen IC. Pre-natal undernutrition, glucocorticoids and the programming of adult hypertension. Clin Exp Pharmacol Physiol. 2001;28:938-41.

Freedman DS, Dietz WH, Srivasan SR \& Bereson GS. The relation of overweight to cardiovascular risk factors among children and adolescentes: the Bogalusa Heart Study. Pediatrics. 1999; 103(6), 1175-82.

Freedman DS, Serdula MK, Srinivasan SR \& Berenson G. Relation of circumference and skinfold thickness to lipid and insulin concentrations in children and adolescents: the Bogalusa Heart Study. Am J Clin Nutr. 1999; 69:308-17.

Freidewald WT, Levy RI, Fredrickson DS. Estimation of the concentration of lowdensity lipoprotein cholesterol in plasma, without use of the preparative ultracentrifuge. Clin Chem 1972; 18: 499-502. 
Fuchs FD. Hipertensão arterial sistêmica. In: Duncan BB et al. Medicina ambulatorial: condutas de atenção primária baseadas em evidências. Porto Alegre: Artmed. 2004; cap 66: 641-56.

Gaskin PS, Walker SP, Forrester TE and Grantham-McGregor SM. Early linear growth retardation and later blood pressure. Eur J Clin Nutr. 2000; 54: 563-567.

Geber ZRS; Zielinsky P. Fatores de risco de aterosclerose na infância. Um estudo epidemiológico. Arq Bras Cardiol. 1997; 69: 231-236.

Giuliano ICB; Coutinho MSSA; Freitas SFT; Pires MMS; Zunino JN; Ribeiro RQC. Lipídes séricos em crianças e adolescentes de Florianópolis, SC: Estudo Floripa Saudável. Arq Bras Cardiol. 2005; 85: 85-91.

Godfrey KM \& Barker DJP. Fetal nutrition and adult disease. Am J Clin Nutr. 2000; 71(suppl):1344S-52S

Guedes DP; Guedes JERP; Barbosa DS; Oliveira JA; Stanganelli LCR. Fatores de risco cardiovasculares em adolescentes: Indicadores biológicos e comportamentais. Arq Bras Cardiol. 2006; 86: 439-50.

Hales CN \& Barker DJP. Type 2 (non-insulin-dependent) diabetes mellitus: the thrifty phenotype hypothesis. Diabetol. 1992; 35 (7): 595-601.

Heyward VH, Stolarczk LM. Avaliação da composição corporal aplicada. Barueri: Editora Manole; 2000. 
Hinchliffe SA, Lynch MR, Sargent PH, Howard CV, Van Velzen D. The effect of intrauterine growth retardation on the development of renal nephrons. Br J Obstet Gynaecol. 1992; 99:296-301.

Huxley RR, Shiell AW, Law CM. The role of size at birth and postnatal catch-up growth in determining systolic blood pressure: a systematic review of the literature. J Hypertens. 2000; 18(7):815-831.

INAN (Instituto Nacional de Alimentação e Nutrição), 1990. Pesquisa Nacional sobre Saúde e Nutrição - PNSN-1989. Arquivo de dados da pesquisa. Brasília. (Mimeo.)

IBGE - Instituto Brasileiro de Geografia e Estatística. Pesquisa Nacional por Amostras de Domicílio, 2003. Indicadores Sociais. Rio de Janeiro. IBGE, 2004.

Jellife DB, Jelliffe EFP. Community nutritional assessment, with special reference to less technically developed countries. 2ed. London: Oxford University Press, 1989.

Kramer MS. The epidemiology if Adverse Pregnancy Outcomes: An Overwiew. J Nutr. 2003; 133: 1592S - 1596S.

Krentz AJ. Insulin resistance: a clinical handbook. $1^{\text {a }}$ ed. Oxford: Blackwell Science, 2002.

Law CM, Barker DJP, Bull AR, et al. Maternal and fetal influences on blood pressure. Arch Dis Child. 2000;66:1291-5. 
Law CM. Significance of birthweight for the future. Archives of Disease in Childhood: Fetal and Neonatal. 2002, 86: F7-F8.

Lewington S, Clarke R, Qizilbash N, Peto R, Collins R, for the Prospective Studies Collaboration. Age-specific relevance of usual blood pressure to vascular mortality: a meta analysis of individual data for one million adults in 61 prospective studies. Lancet 2002; 360:1903-13.

Li C, Huang TT-K, Cruz M L and Goran MI. Birth weight, puberty, and systolic blood pressure in children and adolescents: a longitudinal analysis. J Human Hypertens. 2006; 20: 444-450.

Lucas A, Fewtrell MS, Cole TJ. Fetal origins of adult disease - the hypothesis revisited. BMJ. 1999. 391: 245-9.

Launer LJ, Masaki K, Petrovitch H, Foley D, Havlik RJ. The association between midlife blood pressure levels and late-life cognitive function. The Honolulu-Asia Aging Study. JAMA 1995;274:1846-1851.

Langley-Evans SC. Fetal programming of cardiovascular function through exposure to maternal undernutrition. Proc Nutr Soc. 2001;60:505-513.

Mahoney LT, Clarke WR, Burns TL, Lauer RM. Childhood predictors of high blood pressure. Am J Hypertens. 1991;4: 608-610.

Mast, M.; Kortzinger I.; Konig E.; Muller M.J. - Gender differences in fat mass of 5-7 year old children. Int J Obes Relat Metab Disord, 22(9): 878-84, 1998. 
McCarthy HD, Jarret KV, Crawley HF. The development of waist circumference percentiles in Bristsh children aged 5.0-16.9 y. Eur J Clin Nutr. 2001; 55:902-7.

Menezes AMB, Barros FC, Victora CG, Tomazi E, Halpern R, Oliveira ALB. Risk factors for neonatalmortality in Pelotas, RS. Rev Saúde Pública 1998; 32(3): 2209-16.

Medronho AR. Epidemiologia. São Paulo: Atheneu; 2003.

Meshari AA, De Silva S, Rahman I. Fetal macrosomia - Maternal risks and fetal outcome. Int J Gynaecol Obstet 1990; 32(3):215-22.

Ministério da Saúde do Brasil. Secretaria de Política de Saúde. Organização Pan Americana de Saúde. Guia alimentar para crianças menores de 2 anos. Brasília: MS; 2002.

Monteiro CA, Mondini L, Ortiz LP. Evolução da mortalidade infantil e do retardo do crescimento nos anos 90: causas e impacto sobre desigualdades regionais. In: Monteiro CA. Velhos e novos males de saúde no Brasil: a evolução do país e suas doenças. 2a ed. São Paulo: HUCITEC/NUPENS/USP; 2000. p. 393-420.

Monteiro CA, Benício MHA, Ortiz LP. Tendência secular do peso ao nascer na cidade de São Paulo (1976-1998). Rev Saúde Pública. 2000; 34 (suppl6): 26-40. 
Morais Neto OL, Barros MBA. Risk factors for neonatal and post neonatal mortality in the Central-West region of Brazil: linked use of life-birth and infant death records. Cad Saúde Pública 2000; 16(2): 477-85.

Moreno LA, Fleta J, Mur L, Sarria A \& Bueno M. Distribution in obese and nonobese children and adolescents. J Pediatr Gastroenterol Nutr. 1998; 27:17680.

Morrison JA, James FW, Sprecker DL, Khoury PR, Daniels SR. Sex and race differences in cardiovascular disease risk factor changes in schoolchildren, 19751990; The Princeton School Study. Am J Public Health 1999; 89: 1708-14.

National Heart, Lung, and Blood Institute. Update on the 1987 Task Force Report on High Blood Pressure in Children and Adolescents: A Working Group Report from the National High Blood Pressure Education Program. Pediatrics 1996; 98: 649-56.

National High Blood Pressure Education Program Working Group on High Blood Pressure in Children and Adolescents. The Fourth Report on the Diagnosis, Evaluation, and Treatment of High Blood Pressure in Children and Adolescents. Pediatrics. 2004; 114 (2):555-576.

Pan-American Health Organization. Nutrition, Health, and Child Development. Research Advances and Recommendations. Scientific Publication. 1998; 10:566

Pearce MS, O`Sullivan JJ. Relationship between birth weight and blood pressure variability in children. J of Hum Hypertension. 2003; 17: 677-680. 
Pribylova H, Dvorakova L. Long-term prognosis of infants of diabetic mothers. Relationship between metabolic disorders in newborns and adult offspring. Acta Diabetol. 1996; 33(1):30-4.

Rondó PHC, Ferreira RF, Nogueira F, Ribeiro MCN, Lobert H, Artes R. Maternal psychological stress and distress as predictors of low birth weight, prematurity and intra- uterine growth retardation. Eur J Clin Nutr. 2003; 57: 266-272.

Rostand SG, Cliver SP and Robert LG. Racial disparities in the association of fetal growth retardation to childhood blood pressure. Nephrol Dial Transplant. 2005; 20: $1592-1597$.

Rose G. Sick individuals and sick populations. Int J Epidemiol. 1985; 14: 32-8.

Rosenbloom AL. Fetal Nutrition and insulin sensitivity: The genetic and environmental aspects of "thrift". J Pediatr. 2002; 141(4): 459-61.

Ribeiro RQC; Lotufo PA; Lamounier JA; Oliveira RG; Soares JF; Botter DA. Fatores adicionais de risco cardiovascular associados ao excesso de peso em crianças e adolescentes. O estudo do coração de Belo Horizonte. Arq Bras Cardiol. 2006; 86:408-8.

Seill JC, Perusse L, Despres JP \& Bouchard C. Waist and hip circumferences have independent and opposite effects on cardiovascular disease risk factors: the Quebec Family Study. Am J Clin Nutr. 2001; 74:315-21. 
Schreuder MF \& Nauta J. Prenatal programming of nephron number and blood pressure. Kidney International. 2007; 72: 265-268.

Sichieri R.; Coitinho D.C.; Leão M.M.; Recine E.; Everhart J.E. High temporal, geographic and income variation in body mass index among adults in Brazil. Am J Public Health 1994; 84: 793-8.

Seckl JR, Benediktsson R, Lindsay RS, Brown RW. Placental 11 betahydroxysteroid dehydrogenase and the programming of hypertension. J Steroid Biochem Mol Biol.1995; 55:447-55.

Singhal A, Cole TJ, Lucas A. Early nutrition in preterm infants and later blood pressure: two cohorts after randomized trials. Lancet 2001; 357:413-9.

Sociedade Brasileira de Cardiologia. I Diretriz de prevenção da aterosclerose da infância e na adolescência. Arq Bras Cardiol. 2005; 16-40.

Sociedade Brasileira de Nefrologia. www.sbn.org.br/previna.htm [acesso em 09.01.2006]

Sorof JM, Martin JTDS, Garcia K, Garami Z, Alexandrov AV, Wan F, Portman RJ. Cardiovascular Risk Factors and Sequelae in Hypertensive Children Identified by Referral Versus School-Based Screening. Hypertens. 2004;43:214.

Statacorp. Stata statistical software: release 4.0 [software]. College Station: Stata Corporation; 1995. 
UNICEF - Fundo das Nações Unidas para a Infância. Situação da Infância Brasileira 2001. Brasília: UNICEF, 2001.

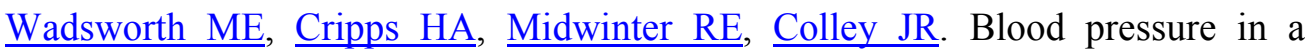
national birth cohort at the age of 36 related to social and familial factors, smoking, and body mass. Br Med J (Clin Res Ed). 1985; 291(6508):1534-8.

Walker BR, Best R, Shackleton CH, Padfield PL, Edwards CR. Increased vasoconstrictor sensitivity to glucocorticoids in essential hypertension. Hypertension. 1996;27:190-96.

World Health Organization. Physical status: the use and interpretation of anthropometry.Technical Report Series.854. Geneva: World HIth Stat.1995.

World Health Organization. The World Health Report. Reducing risks, promoting healthy life. Geneva: World Health Organization. 2002.

World Health Organization. Diet, Nutrition and Prevention of Choronic Diseases. Report FAO/WHO Expert Consulation. WHO Technical Report Series 916. Geneva; 2003.

Williams RL, Creasy RK, Cunninghan GC, Hawes WE, Norris FD, Tashiro M. Fetal Growth and Perinatal Viability in Califórnia. Obstetrics \& Gynecology. 1982; 59: 624-632. 
Yajnik CS. Interactions of perturbations in intrauterine growth during childhood on the risk of adult-onset disease. Proc Nutr Soc. 2000; 59:257-265.

Yajnik CS. The lifecycle effects of nutrition and body size on adult adiposity, diabetes and cardiovascular disease. Obes Res 2002, 3(3): 217-24. 
$\underline{\text { ANEXOS }}$ 


\section{Anexo I}

TERMO DE CONSENTIMENTO LIVRE ESCLARECIDO

$\mathrm{Eu}$,

declaro

que

voluntariamente

participarei

e autorizo

meu filho

(a)

a participar da pesquisa

intitulada: "Efeito do peso ao nascimento no desenvolvimento de resistência a insulina, obesidade e hipertensão em crianças de 3 a 6 anos de idade no município de Jundiaí, São Paulo" sob responsabilidade da equipe coordenada pelas pesquisadoras Joilane Alves Pereira, Jesuana Oliveira Lemos e Patrícia Helen de Carvalho Rondó. N ${ }^{\circ}$

Fui esclarecido que:

- O objetivo do trabalho é investigar as relações entre peso ao nascimento e desenvolvimento de diabetes, aumento da pressão arterial e obesidade.

- Meu filho realizará um exame de sangue para o qual serão necessárias $10 \mathrm{~h}$ de jejum a partir do dia anterior. Para este exame será coletada uma amostra de sangue de aproximadamente $10 \mathrm{ml}$.

- O estado nutricional do meu filho será avaliado através de medidas de peso, altura, cintura, quadril, braço e tórax; além de avaliar a quantidade de gordura do corpo.

- A composição corporal do meu filho será medida por meio de aparelho de bioimpedância, sem nenhum risco á saúde ou qualquer incômodo.

- Meu filho poderá ser sorteado para realizar outra medida de gordura do corpo por meio de um aparelho de desintometria, em clínica especializada, com pessoal treinado e qualificado.

- Meu filho também terá a pressão arterial medida, por meio de equipamento próprio. 
- Responderei a um questionário com perguntas referentes às condições de vida da minha família (escolaridade, renda, dentre outras questões), bem como sobre a alimentação do meu filho.

- Este trabalho não envolve nenhum risco a saúde do meu filho.

- As informações obtidas são sigilosas e meu nome, bem como o nome do meu filho não será divulgado.

- Estou livre para desistir de participar da pesquisa a qualquer momento, sem nenhum constrangimento ou prejuízo para mim ou para minha família, bem como posso solicitar esclarecimento sobre qualquer dúvida que surgir em relação a esta pesquisa.

Local e data:

, 1

Assinatura do participante:

Assinatura do entrevistador:

Assinatura do pesquisador:

Informações: Patrícia H. C. Rondó, Faculdade de Saúde Pública - USP; Av Dr. Arnaldo, 715. São Paulo/SP. Tel. (11) 3066-7771/7705 Ramal 234.

Joilane Alves Pereira/ Jesuana Oliveira Lemos: (11) 4607-6623 Jundiaí_ SP 


\section{ANEXO II}

\begin{tabular}{l}
\hline UNIVERSIDADE DE SÃO PAULO \\
FACULDADE DE SAÚDE PÚBLICA \\
DEPARTAMENTO DE NUTRIÇÃO \\
Av. Dr. Arnaldo, 715 - Cerqueira Cesar \\
CEP: 01246-904 São Paulo/SP \\
Tel.: (011) 3061-7762/7705/7771 \\
\hline
\end{tabular}

Formulário de Entrevista Data da entrevista:

Resposta (88): não se aplica

(99): não sabe a resposta

\section{Identificação}

Nome do entrevistador: $\mathrm{N}^{\mathrm{o}}$ de identificação:

Nome da criança: (Não abreviar)

Data de nasc.:

Nome da mãe:

$\mathrm{N}^{\mathrm{o}}$

Endereço da mãe ou responsável:

\section{(Avenida, rua, número, apartamento, bairro - não abreviar)}

Telefone: contato (recado):

celular:.

Nome, endereço e telefone de um parente ou amigo:

UBS ou serviço médico utilizado

Hospital onde nasceu a criança:

Questões a serem respondidas pela mãe da criança ou responsável pelo cuidado direto: CONSTITUIÇÃO FAMILIAR ATUAL

1. Qual a pessoa diretamente responsável pela criança? 
(0) mãe (1) pai (2) avó (3) tia (4) irmã

(5) outros:

especificar:

2. Você é a mãe da criança?

(0) Sim (1) Não, especificar o grau de

parentesco:

3. Qual o seu estado civil?

(0) solteira (1) casada (2) separada/divorciada (3) viúva (4) Mora Junto

4. Idade da mãe: .......... anos

5.Data de nascimento da mãe :

Se não possui companheiro seguir para questão 10

6. O seu marido ou companheiro é o pai da criança?

(0) $\operatorname{Sim} \quad$ (1) Não

7. Qual a idade do pai da criança...........anos

8.Data de nascimento do pai ___

9. Há quanto tempo está com seu companheiro?

(0) menos de 3 meses

(1) de 3 a 6 meses

(2) de 6 a 11 meses

(3) de 1 a 2 anos

(4) mais de 2 anos

10. Com quem mora atualmente? (somente para as mulheres sem companheiro)

(0) mora com os pais/familiares

(1) mora sozinha

(2) mora com amigos

(3) mora com o(s) filho(s)

(4) mora no local de trabalho

(5) outro local. Especificar:

11. Número de pessoas que vivem na sua casa: pessoas.

12. Qual a ordem de nascimento de seu(a) filho(a)?:

(0) primeiro filho (1) segundo filho (2) terceiro filho (3) quarto filho (4)

\section{ESCOLARIDADE}

13. A senhora freqüentou a escola?

(0) Sim (1) Não

14. Durante quantos anos a senhora estudou?

anos (99) não sabe 
15. Qual seu nível de escolaridade:

(0) Fundamental incompleto (até $4^{\mathrm{a}}$ série primária $-1^{\mathrm{o}}$ grau)

(1) Fundamental incompleto (de $5^{\mathrm{a}}$ a $8^{\mathrm{a}}$ série antigo ginásio $-1^{\mathrm{o}}$ grau)

(2) Fundamental completo ( $1^{\mathrm{o}}$ grau completo)

(3) Ensino médio incompleto (colegial incompleto $-2^{\circ}$ grau)

(4) Ensino médio completo ( ${ }^{\circ}$ grau)

(5) Superior incompleto (universidade/faculdade)

(6) Superior completo (universidade/ faculdade)

(7) Outro. Especificar:

(99) não sabe

16. A sra. fez supletivo?

(0) $\mathrm{Sim}$

(1) Não

17. Se sim, qual?

(0) Fundamental incompleto

(1) Fundamental completo $\left(1^{\mathrm{o}}\right.$ grau - até $8^{\mathrm{a}}$ série $)$

(2) Médio completo $\left(2^{\circ}\right.$ grau $)$

18. Quantos anos seu companheiro estudou? anos

(99) não sabe

19. Qual a escolaridade de seu companheiro?

(0) Fundamental incompleto (até $4^{\mathrm{a}}$ série primária $-1^{\mathrm{o}} \mathrm{grau}$ )

(1) Fundamental incompleto (de $5^{\mathrm{a}}$ a $8^{\mathrm{a}}$ série antigo ginásio $-1^{\mathrm{o}}$ grau)

(2) Fundamental completo ( $1^{\mathrm{o}}$ grau completo)

(3) Ensino médio incompleto (colegial incompleto $-2^{\circ}$ grau)

(4) Ensino médio completo ( $2^{\circ}$ grau)

(5) Superior incompleto (universidade/ faculdade)

(6) Superior completo (universidade/ faculdade)

(7) Outro. Especificar:

20. Seu companheiro fez supletivo?

(0) $\operatorname{Sim} \quad$ (1) Não sabe

21. Se sim, qual?

(0) Fundamental incompleto

(1) Fundamental completo $\left(1^{\mathrm{o}}\right.$ grau - até $8^{\mathrm{a}}$ série $)$

(2) Médio completo $\left(2^{\circ}\right.$ grau)

22 e 23- Apenas para quem tem menos de 4 anos de escolaridade ou não freqüentou a escola:

22. A sra. sabe ler e escrever?
(0) $\mathrm{Sim}$
(1) Não

23. Seu companheiro sabe ler e escrever?
(0) $\mathrm{Sim}$
(1) Não

(99) não 
24. Seu filho (a) está freqüentando alguma escola?

(0) Sim, período integral (1) Sim, meio período

(2) Não

25. Seu filho está freqüentando alguma creche?
(0) Sim, período integral
(1) Sim, meio período
(2) Não

26. Se seu filho freqüenta escola, que ano ele está cursando?

(0) Jardim, maternal ou pré-primário.

(1) $1^{\mathrm{a}}$ série do ensino fundamental

(2) $2^{a}$ série do ensino fundamental

(3) Outra:

Especificar:

(99) não sabe

\section{RENDA}

27. Enumere as pessoas que moram no domicílio:

\begin{tabular}{|l|l|l|l|l|}
\hline Pessoa & Idade (anos ou meses) & Sexo & $\begin{array}{l}\text { Parentesco com a } \\
\text { criança }\end{array}$ & $\begin{array}{l}\text { Renda individual } \\
\text { (R\$) }\end{array}$ \\
\hline 1 & & & & \\
\hline 2 & & & & \\
\hline 3 & & & & \\
\hline 4 & & & & \\
\hline 5 & & & & \\
\hline 6 & & & & \\
\hline 7 & & & & \\
\hline 8 & & & & \\
\hline 9 & & & & \\
\hline
\end{tabular}

28. A renda mensal familiar total é de?

reais.

RPC ..R \$

29. Quem é a pessoa que mais contribui para o orçamento familiar? (que ganha mais por mês).

30.Qual é a atividade da pessoa que mais contribui para o orçamento familiar?

31. A sra. trabalha?

(0) Sim (1) Não

32. Se sim, qual é o seu tipo de trabalho?

(0) trabalho doméstico sem remuneração

(1) trabalho doméstico com remuneração

(2) trabalho fora de casa sem remuneração

(3) trabalho fora de casa com remuneração e com vínculo empregatício

(4) trabalho fora de casa com remuneração sem vínculo empregatício (autônoma) 
(5) Outro tipo de trabalho. Especificar:

(99) Não sabe

33.. A família tem algum outro ganho que contribui para a renda familiar? (pensão, aluguel, auxílio do governo, etc.).
(0) $\mathrm{Sim}$
(1) Não

34. Qual o valor aproximado de outras rendas? reais

35. A família recebe cesta básica?

(0) Sim, regularmente.

(1) Sim, irregularmente. Especificar $n^{\circ}$ de vezes no último ano vezes.

(2) Não.

\section{CONDIÇÕES DE MORADIA}

36. Há quantos anos seu (a) filho (a) vive na mesma cidade? anos

37. Há quantos anos seu (a) filho (a) vive na mesma casa? anos

38. A casa em que vocês vivem é:

(0) Própria (1) Financiada (2) Alugada (3) Emprestada/cedida (4) Invadida (9) Não sabe

39. Qual o tipo de casa?

(0) tijolos (1) taipa (2) mista - tijolo e taipa (3) outros

40. Tem água encanada?

(0) sim, dentro de casa (1) sim, no quintal (2) não

41. Tem energia elétrica:

(0) sim, rede de pública (1) sim, através de extensão (2) não

42. Como é a privada da casa?

(0) sanitário com descarga (1) sanitário sem descarga (2) casinha (3) não tem

43. Qual o destino do lixo?

(0) coleta pública (1) queimado (2) enterrado (3) céu aberto

44. Quantos cômodos têm na sua casa? (incluindo banheiros e cozinhas)................ ômodos

45. Quais destes aparelhos existem em sua casa. Quantos de cada um?

\begin{tabular}{|l|l|l}
\hline Identificação & Aparelho & Quantidade \\
\hline
\end{tabular}




\begin{tabular}{|l|l|l|}
\hline 0 & Refrigerador & \\
\hline 1 & Aspirador de pó & \\
\hline 2 & Freezer & \\
\hline 3 & Máquina de Lavar roupa & \\
\hline 4 & Forno Microondas & \\
\hline 5 & Ar condicionado & \\
\hline 6 & Fogão & \\
\hline 7 & Linha de telefone & \\
\hline 8 & Celular & \\
\hline 9 & TV & \\
\hline 10 & Automóvel & \\
\hline 11 & Moto & \\
\hline 12 & Bicicleta & \\
\hline
\end{tabular}

QUESTÕES SOBRE SAÚDE

46 Seu filho (a) foi internado alguma vez? Se não, pular para questão 51.

(0) Sim, quantas vezes?................... (1) Não

47. Qual o motivo da internação?.

48. Qual das doenças a seguir seu filho já teve?

\begin{tabular}{|l|l|l|l|}
\hline Doença & Até 1 ano & Acima de 1 ano & Idade \\
\hline Diarréia & & & \\
\hline Pneumonia & & & \\
\hline Asma, bronquite & & & \\
\hline Parasitoses intestinais & & & \\
\hline Dermatoses & & & \\
\hline Otite média & & & \\
\hline Anemia & & & \\
\hline Varicela & & & \\
\hline Rubéola & & & \\
\hline Sarampo & & & \\
\hline Outras & & & \\
\hline
\end{tabular}

49. Seu filho faz uso de algum medicamento, incluindo-se suplementos vitamínicos?

(0) Sim, qual?

(1) Não

50. Seu filho tomou alguma das seguintes vacinas?

\begin{tabular}{|l|l|l|l|}
\hline & Vacina & Sim & Não \\
\hline 1 & BCG & & \\
\hline 2 & DPT & & \\
\hline 3 & Sabin & & \\
\hline 4 & Sarampo & & \\
\hline
\end{tabular}


\begin{tabular}{|l|l|l}
\hline 5 & Outras \\
\hline
\end{tabular}

51. A senhora e o pai da criança têm ou tiveram alguma das doenças citadas a seguir? Marque também a idade em que estas doenças apareceram.

\begin{tabular}{|l|l|l|l|l|l|l|}
\hline Doença & \multicolumn{1}{l}{$\begin{array}{l}\text { Pai } \\
\text { Sim Não idade }\end{array}$} & \multicolumn{1}{l}{ Sim } & \multicolumn{1}{l|}{ Não } & \multicolumn{1}{l|}{ Idade } \\
\hline Hipertensão arterial & & & & & & \\
\hline Diabetes Mellitus & & & & & & \\
\hline Asma ou bronquite & & & & & & \\
\hline Obesidade & & & & & & \\
\hline $\begin{array}{l}\text { Hipercolesterolemia (colesterol } \\
\text { elevado) }\end{array}$ & & & & & & \\
\hline $\begin{array}{l}\text { Hipertrigliceridemia (triglicérides } \\
\text { elevados) }\end{array}$ & & & & & & \\
\hline Artrite, outro reumatismo & & & & & & \\
\hline Osteoporose & & & & & & \\
\hline Deformidade óssea & & & & & & \\
\hline Dor no peito, aperto, angina & & & & & & \\
\hline Infarto do Miocárdio & & & & & & \\
\hline Acidente vascular cerebral (derrame) & & & & & & \\
\hline Trombose, flebite & & & & & & \\
\hline Embolia Pulmonar & & & & & & \\
\hline Pneumonia & & & & & \\
\hline Outros & & & & & \\
\hline
\end{tabular}

52. Você ou o pai da criança têm outros parentes (avós, irmãos ou filhos) que têm ou tiveram qualquer das doenças acima?
(0) $\operatorname{Sim}$
(1) Não

\begin{tabular}{|l|l|l|l|l|l|l|}
\hline Doença & \multicolumn{2}{l|}{$\begin{array}{l}\text { Avô Avó Outros } \\
\text { Paternos }\end{array}$} & \multicolumn{2}{l}{$\begin{array}{l}\text { Avô Avó Outros } \\
\text { Maternos }\end{array}$} \\
\hline Hipertensão arterial & & & & & & \\
\hline Diabetes Mellitus & & & & & & \\
\hline Asma ou bronquite & & & & & & \\
\hline Obesidade & & & & & & \\
\hline $\begin{array}{l}\text { Hipercolesterolemia (colesterol } \\
\text { elevado) }\end{array}$ & & & & & \\
\hline $\begin{array}{l}\text { Hipertrigliceridemia (triglicérides } \\
\text { elevados) }\end{array}$ & & & & & & \\
\hline Artrite, outro reumatismo & & & & & & \\
\hline Osteoporose & & & & & & \\
\hline Deformidade óssea & & & & & & \\
\hline Dor no peito, aperto, angina & & & & & & \\
\hline Infarto do Miocárdio & & & & & & \\
\hline
\end{tabular}




\begin{tabular}{|l|l|l|l|l|l|l|}
\hline Acidente vascular cerebral (derrame) & & & & & & \\
\hline Trombose, flebite & & & & & & \\
\hline Embolia Pulmonar & & & & & & \\
\hline Pneumonia & & & & & & \\
\hline Outros & & & & & & \\
\hline
\end{tabular}

53. Observações: (anotar tudo que possa parecer importante como, por exemplo, não saber das enfermidades dos pais por não ter convivido com eles).

\section{ALIMENTAÇÃO}

54. Até que idade seu filho foi amamentado exclusivamente no peito?. ..meses/dias

55. Quando foi introduzido algum tipo de líquido (água, suco, chás)?Qual?

56. Durante quanto tempo seu filho recebeu leite materno mesmo em aleitamento misto?

meses/anos

57. Quais as razões que levaram ao desmame no peito? Assinale SIM para quantas alternativas forem necessárias.

\begin{tabular}{|l|l|l|l|}
\hline & Motivo & Sim & Não \\
\hline 1 & O leite era fraco & & \\
\hline 2 & Não tinha leite & & \\
\hline 3 & O bebê sentia fome & & \\
\hline 4 & O bebê ficou doente. Se sim qual a doença & & \\
\hline 5 & Peito machucado, dor ao amamentar & & \\
\hline 6 & Trabalho fora de casa & & \\
\hline 7 & O bebê foi para a creche & & \\
\hline 8 & Outro motivo & & \\
\hline & & & \\
\hline 88 & Não sabe & & \\
\hline 99 & Não se aplica & & \\
\hline
\end{tabular}

58. Alguém orientou a introdução de outros alimentos

(0) Conta própria (1) Médico (2)Outra. Quem?.

59. Quando foi introduzido o primeiro alimento não-líquido? (papinha, fruta, mingau, etc)

dias/meses 
60.Qual?

61.Qual o local onde a criança faz o maior número de refeições por dia?

(0) em casa (1) na creche ou escolinha (2) em casa de parentes (avó, tios, responsável)

62.Quantas latas de óleo a sra. utiliza por mês em casa?

latas

63.Quantos quilos de sal a sra utiliza por mês no preparo da comida? $\mathrm{kg}$

64. Quantas vezes o seu filho (a) costuma comer alimentos fritos (batata frita, bife frito, frango frito, etc).

(0) todos os dias ( 5 a $7 \times$ por semana)

(1) Semanalmente ( 2 a 4 x por semana)

(2) Mensalmente (1 a 4 x por mês)

65. Seu filho costuma adicionar sal à comida pronta?

(0) Sim (1) Não 


\section{ANEXO III}

Dia alimentar habitual

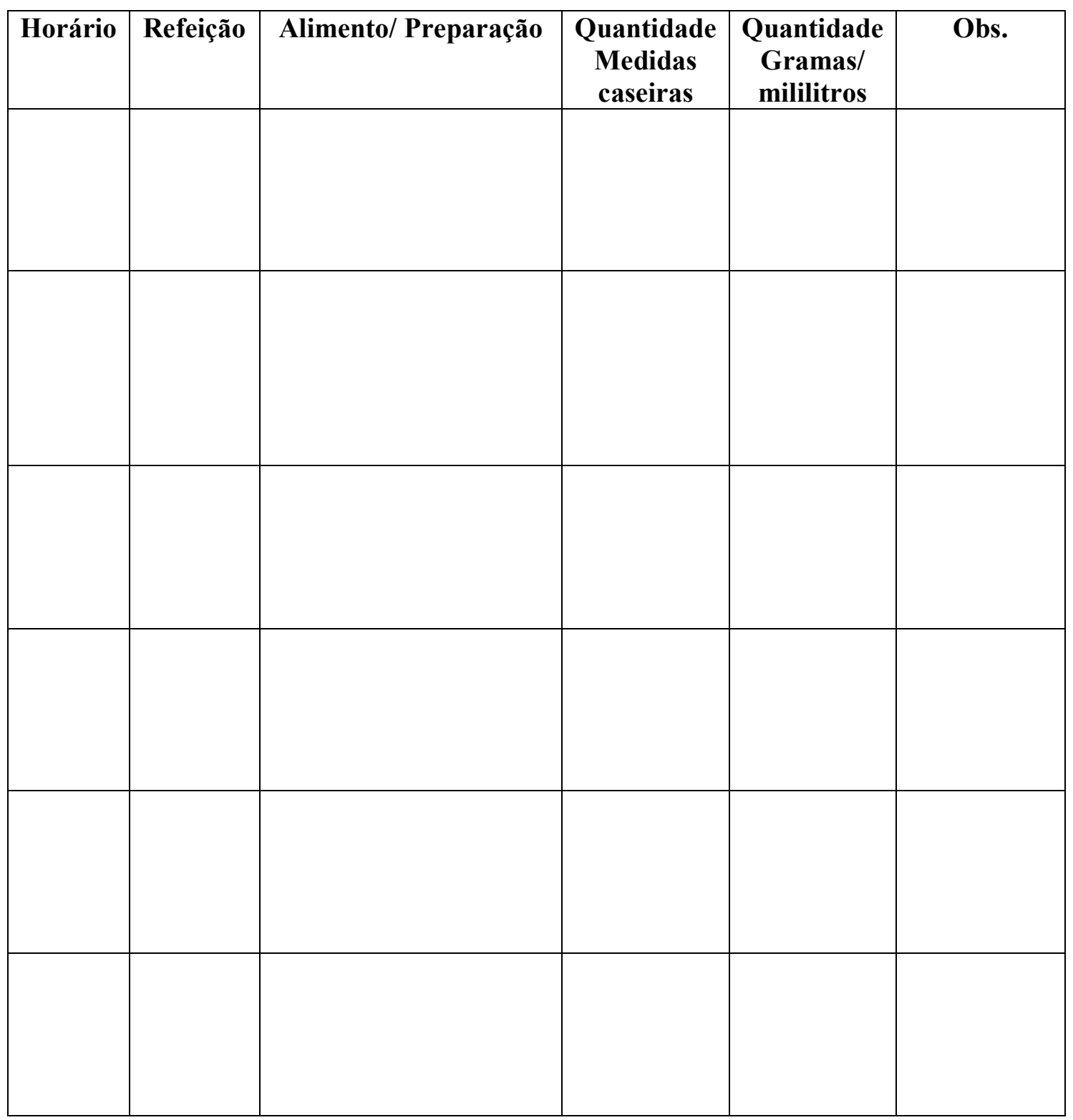




\section{ANEXO IV}

\section{FORMULÁRIO DA ANTROPOMETRIA}

Nome do avaliador:

Data da avaliação:

Nome da mãe:

Nome da criança:

1. Data de nascimento:

2. Idade: anos meses

3. Sexo

(0) Masculino

(1) Feminino

\begin{tabular}{|l|l|l|l|l|l|}
\hline & $1^{\text {a }}$ medida & $2^{\text {a }}$ medida & $3^{\text {a }}$ medida & $\begin{array}{l}\text { Média } \\
\text { final }\end{array}$ & $\begin{array}{l}\text { Grau de } \\
\text { Dificuldade }\end{array}$ \\
\hline 4. Peso (kg) & & & & & \\
\hline $\begin{array}{l}\text { 5. Altura (cm) } \\
\text { do braço (cm) }\end{array}$ & & & & & \\
\hline $\begin{array}{l}\text { 7. Circunferência } \\
\text { do Tórax (cm) }\end{array}$ & & & & & \\
\hline $\begin{array}{l}\text { 8. Circunferência } \\
\text { da cintura (cm) }\end{array}$ & & & & & \\
\hline $\begin{array}{l}\text { 9. Circunferência } \\
\text { do quadril (cm) }\end{array}$ & & & & & \\
\hline $\begin{array}{l}\text { 10. Dobra cutânea } \\
\text { triciptal (mm) }\end{array}$ & & & & & \\
\hline $\begin{array}{l}\text { 11. Dobra cutânea } \\
\text { subescapular } \\
\text { (mm) }\end{array}$ & & & & & \\
\hline $\begin{array}{l}\text { 12. } \\
\text { Bioimpedância } \\
\text { resistência }\end{array}$ & & & & & \\
\hline $\begin{array}{l}\text { 13. } \\
\text { Bioimpedância } \\
\text { Reactância }\end{array}$ & & & & & \\
\hline $\begin{array}{l}\text { 14. Dexa } \\
\text { \% gordura }\end{array}$ & & & & & \\
\hline
\end{tabular}




\section{ANEXO V}

Valores de referência lipídica propostos para a faixa etária de 2 a 19 anos, de acordo com a Sociedade Brasileira de Cardiologia (2005).

\begin{tabular}{cccc}
\hline \hline Lipídeos & Desejáveis (mg/dl) & Limítrofes (mg/dl) & Aumentados (mg/dl) \\
\hline \hline CT & $<150$ & $150-169$ & $\geq 170$ \\
LDL_c & $<100$ & $100-129$ & $\geq 130$ \\
HDL-C & $\geq 45$ & & $\geq 130$ \\
TG & $<100$ & $100-129$ & \\
\hline \hline
\end{tabular}

Valores de referência para Peso ao Nascimento. OMS 1977.

\begin{tabular}{cccc}
\hline \hline baixo & Insuficiente & Adequado & Elevado \\
\hline \hline$<2500$ & $\geq 2500-2999$ & $3000-3499$ & $>3500$ \\
\hline \hline
\end{tabular}

Valores de referência para Idade gestacional (meses). OMS 1977.

\begin{tabular}{cccc}
\hline \hline & Pré-termo & A termo & Pós-termo \\
\hline \hline $\begin{array}{c}\text { Idade } \\
\text { Gestacional } \\
\text { (IG) }\end{array}$ & $<37$ & $37-42$ & $>42$ \\
\hline \hline
\end{tabular}


Valores de referência para IMC em percentil, segundo CDC 2000.

\begin{tabular}{|l|l|}
\hline \hline Categorias & Percentil \\
\hline \hline Baixo Peso & percentil $<5$ \\
\hline Normal & $5 \leq$ Percentil $<85$ \\
\hline Risco de sobrepeso & Percentil $\geq 85$ \\
\hline Sobrepeso & Percentil $\geq 95$ \\
\hline \hline
\end{tabular}

Classificação da PA em crianças e adolescentes: Nomenclatura Critério. Proposta pelo: The fourth report on the diagnosis, evaluation, and treatment of high blood pressure in children and adolescents

- Normal: PAS e PAD em percentis ${ }^{*}<90$.

- Pré-hipertensão: PAS e/ou PAD em percentis* $>90$ e $<95$ ou sempre que $\mathrm{PA}>120 / 80 \mathrm{mmHg}$.

- HAS estágio 1: PAS elou PAD em percentis* entre 95 e 99 acrescido de $5 \mathrm{mmHg}$.

- HAS estágio 2: PAS e/ou PAD em percentis* > 99 acrescido de $5 \mathrm{mmHg}$.

*Para idade, sexo e percentil de altura, em três ocasiões diferentes. 